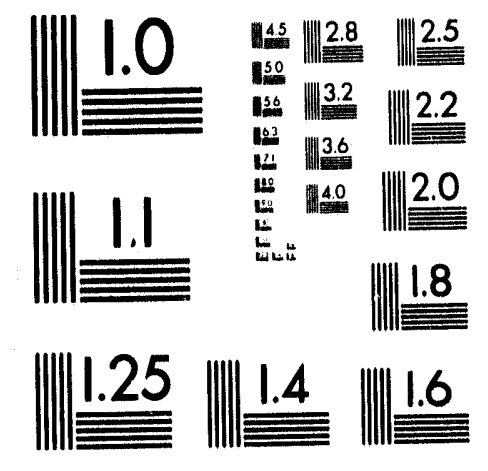



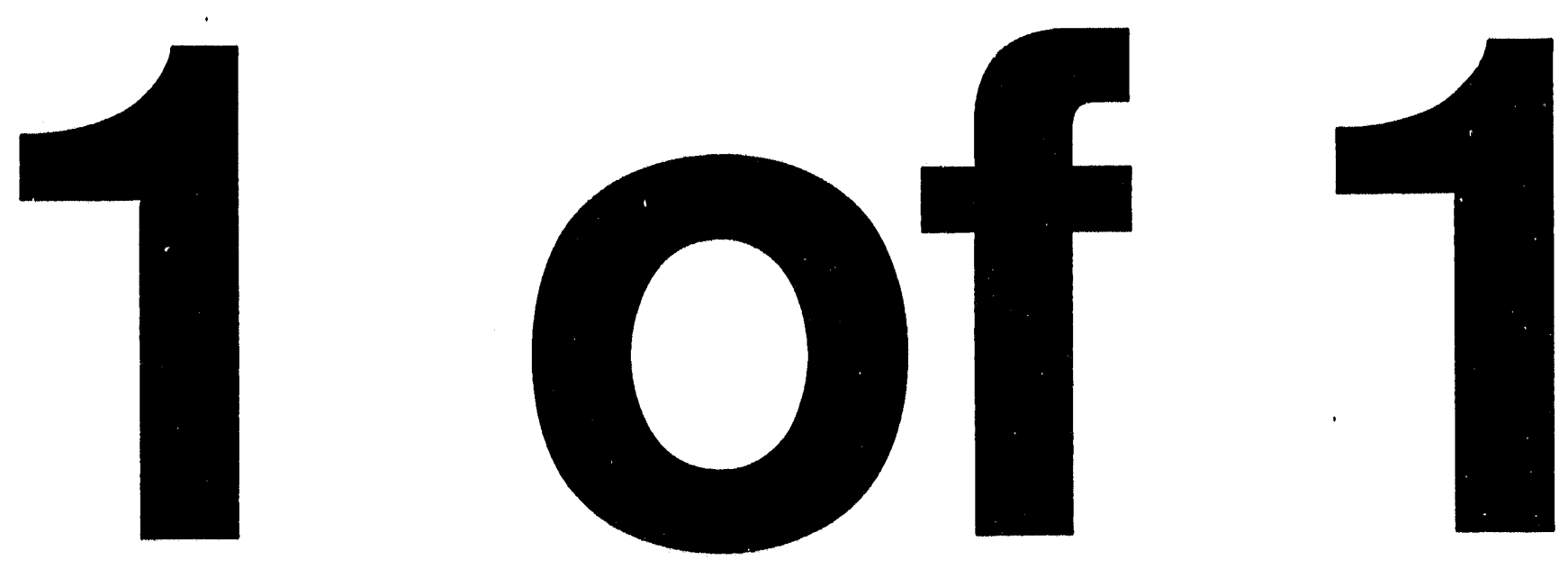


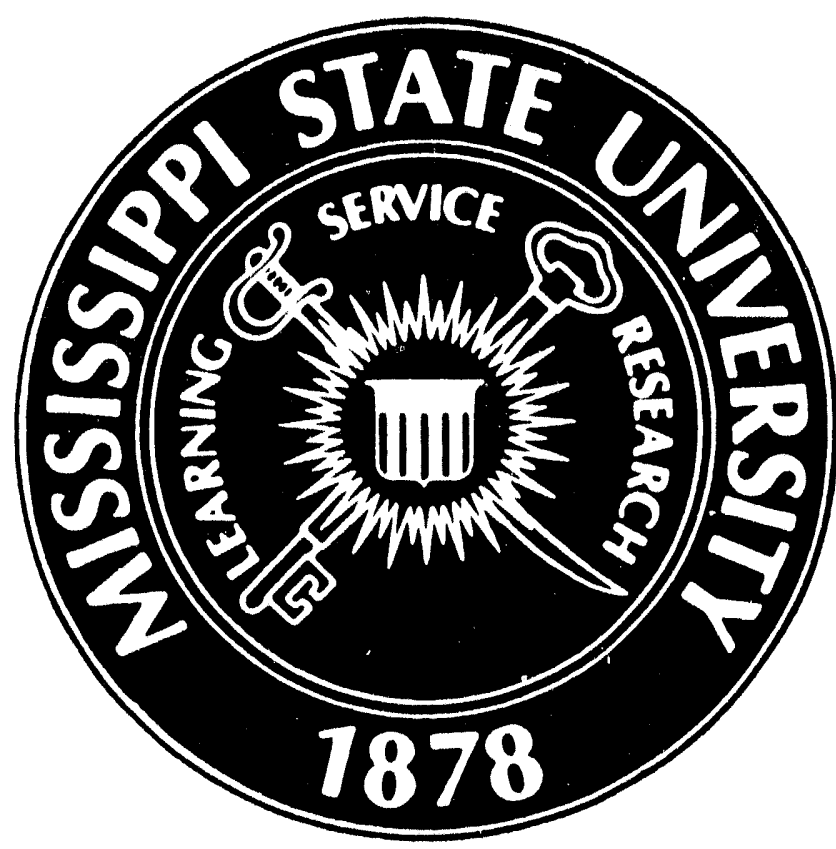

$$
\begin{gathered}
\text { HE. IVED } \\
\text { SEP } 271993 \\
\text { USTI }
\end{gathered}
$$

\section{DIAGNOSTIC INSTRUMENTATION AND ANALYSIS LABORATORY}

DIAGNOSTIC DEVELOPMENT AND SUPPORT OF MHD TEST FACILITIES

Technical Progress Report for the period January, February, March 1991

Prepared for the United States Department of Energy Under Contract No. DE-AC02-80ET-15601 


\title{
DIAGNOSTIC DEVELOPMENT AND SUPPORT OF MHD TEST FACILITIES
}

\author{
Technical Progress Report \\ for the period \\ January, February, March 1991
}

W. S. Shepard, Director

R. L. Cook, Deputy Director

\section{Diagnostic Instrumentation and Analysis Laboratory Mississippi State University \\ Mississippi State, Mississippi 39762 \\ DISCLAIMER}

This report was prepared as an account of work sponsored by an agency of the United States Government. Neither the United States Government nor any agency thereof, nor any of their employees, makes any warranty, express or implied, or assumes any legal liability or responsibility for the accuracy, completeness, or usefulness of any information, apparatus, product, or process disclosed, or represents that its use would not infringe privately owned rights. Reference herein to any specific commercial product, process, or service by trade name, tradenatark, manufacturer, or otherwise does not necessarily constitute or imply its endorsement, recommendation, or favoring by the United States Government or any agency thercof. The views and opinions of authors expressed herein do not necessarily state or reflect those of the United States Government or any agency thereof.

$$
\begin{gathered}
\text { Prepared for the United States } \\
\text { Department of Energy }
\end{gathered}
$$

Under Contract No. DE-AC02-80ET-15601 
This report was prepared as an account of work sponsored by the United States Government. Neither the United States nor the United States Department of Energy, nor any of their employees, makes any warranty, expressed or implied, or assumes any legal liability or responsibility for the accuracy, completeness, or usefulness of any information, apparatus, product, or process disclosed, or represents that its use would not infringe privately owned rights. Reference herein to any specific commercial product, process, or service by trade name, mark, manufacturer, or otherwise, does not necessarily constitute or imply its endorsement, recommendation, or favoring by the United States Government or any agency thereof. The views and opinions of authors expressed herein do not necessarily state or reflect those of the United States Government or any agency thereof. 
List of Figures . . . . . . . . . . . . . . . . . . . . iv

List of Tables. . . . . . . . . . . . . . . . . . . . v

Nomenclature . . . . . . . . . . . . . . . . . . . . . vi

Abstract . . . . . . . . . . . . . . . . . . . . . . . . 1

Project Objectives . . . . . . . . . . . . . . . . . . . 2

Project Description . . . . . . . . . . . . . . . . . . . . . 5

Description of Facilities . . . . . . . . . . . . . . . . . 28

Technical Progress . . . . . . . . . . . . . . . . . . 29

Task 1. Diagnostic Instrument Development . . . . . . . . . . 30

A. Coherent Anti-stokes Raman Spectroscopy

System (CARS) . . . . . . . . . . . . . . . . 30

B. Particle Size Distribution System (PSD) . . . . . . . 48

C. Potassium Emission/Absorption System (PE/AS) . . . . 49

D. Intrusive Multi-Probe System (IMPS) . . . . . . . . . 50

E. Faraday Rotation System (FRS) . . . . . . . . . . . . 51

F. Multi-Purpose Imaging System (MPIS) . . . . . . . . . 52

G. Differential Absorption Laser Spectroscopy

System (DALAS) . . . . . . . . . . . . . . . . . 53

H. Laser Optogalvanic Spectroscopy System (LOGS) . . . . 56

I. Cross Correlation System (CCS) . . . . . . . . . 58

Task 2. Test Stand Operations . . . . . . . . . . . . . . 59

A. Test Stand Modifications . . . . . . . . . . . . 59

B. Test Stand Runs... . . . . . . . . . . . . 59

Task 3. Technical Support for National MHD Programs . . . . 60

A. Field Measurements . . . . . . . . . . . . . . . . 60

B. Field Tests/Instrument Modifications . . . . . . . . 60

C. Field Operations/Developing Systems . . . . . . . . . 60

Task 4. Project Management . . . . . . . . . . . . . 61

Task 5. Technology Transfer . . . . . . . . . . . . 62 


\section{LIST OF FIGURES}

1.A.1 Fitting of a bimodal test spectrum with single temperature model. Each fitted data point was weighted equally. . . . . . . . . . . . . . . . 32

1.A.2 Fitting of a bimodal test spectrum with single temperature model. Each fitted data point was weighted inversely proportional to its intensity. . 33

1.A.3 Model calculation showing contribution of CARS signal generated from all regions across a gas stream. . . . . . . . . . . . . . 36

1.A.4 Temperature profiles. . . . . . . . . . . . . 39

1.A.5 Temperature profile of flat flame burner $10 \mathrm{~mm}$ from the burner surface with folded BOXCARS and a $30-\mathrm{cm}$ focal length lens . . . . . . . . . . .

1.A.6 $\mathrm{N}_{2}$ CARS spectra recorded at center of DIAL test stand with collinear CARS and $\mathrm{N}_{2}$ and argon purge. .

1.A.7

Temperature profile across DIAL test stand measured with collinear CARS at a port $87 \mathrm{~cm}$ downstream with $\mathrm{N}_{2}$ and argon purge. . . . . . . .

1.A.8 Temperature profile measured with folded BOXCARS across DIAL test stand at a port $87 \mathrm{~cm}$ downstream from the combustor with $\mathrm{N}_{2}$ and argon purge. . . .

1.G.1 Two-wavelength dye laser for Differential Absorption Laser Spectroscopy System (DALAS). . . 


\section{LIST OF TABLES}

1.A.1 Inferred temperature from a bimodal temperature spectrum . . . . . . . . . . . . . . . . 34

1.A.2 Effect of beam waist and temperature gradient at probed volume to error introduced into temperature measurement. . . . . . . . . . . . . 38 


\section{NOMENCLATURE}

AIAA American Institute of Aeronautics and Astronautics

FWHM full width at half maximum

LMF 4-V Low Mass Flow test designation used by CFFF

mrad milliradians

$\mathrm{mW} \quad$ milliwatts

NA:YAG neodymium: yttrium aluminum garnet

nm nanometer

No nitric oxide

$\mathrm{SO}_{2} \quad$ sulfur dioxide 


\section{ABSTRACT}

The Diagnostic Instrumentation and Analysis Laboratory (DIAL) at Mississippi State University (MSU) is developing diagnostic instruments for magnetohydrodynamic (MHD) power train data acquisition and for support of MHD component development test facilities. Microprocessor-controlled optical instruments, initially developed for Heat Recovery/Seed Recovery (HRSR) support, are being refined, and new systems to measure temperatures and gas-seed-slag stream characteristics are being developed. To further data acquisition and analysis capabilities, the diagnostic systems are being interfaced with DIAL's computers. Technical support for the diagnostic needs of the national MHD research effort is being provided. DIAL personnel also cooperate with government agencies and private industries to improve the transformation of research and development result.s int:o processes, products and services applicable to their needs. 


\section{PROJECT OBJECTIVES}

Diagnostic and special instrumentation beyond that which is normally required for appropriate control and operation of an electrical power production facility is required for an MHD power system. The Department of Energy's (DOE) coal-fired MHD proof-ofconcept program serves as the precursor to larger scale demonstration facilities and commercially-implemented plants. In order that the transition to commercially feasible plant designs be made quickly and effectively, it is essential to determine as much as possible about the detailed component operation of the MHD power train and the HRSR system.

Conventional diagnostic sensors are of limited use in characterizing the MHD gas stream, and special diagnostic instrumentation systems are needed to provide the means to monitor and collect engineering data to determine specific parameters, both baseline values and fluctuations; and to provide background information for continuing MHD development, solutions to technological barriers, and a basis for future plant designs. Accurate characterization of the thermal, chemical and flow properties is essential for future design optimization.

The scale-up process is a nonlinear extrapolation because many of the physical processes are nonlinear. To decrease the uncertainties in this nonlinear extrapolation to a new, larger design, it is necessary to rely not only on engineering experience with smaller systems, but also on mathematical models which describe the physical processes and the manner in which they behave as design variables are changed. Mathematical models require the input of detailed data; the greater the quanticy and quality of data, the more accurate the model and the smaller the uncertainty in the extrapolation to larger designs.

The baseline data obtained by diagnostic measurements at the Component Development and Integration Facility (CDIF) and Coal-Fired Flow Facility (CFFF) are providing important engineering experience and data for developing appropriate analytical models. Tests of these models, as well as information to further develop these design models, will be provided by diagnostic measurements on these facilities. These measurements are essential to minimize the technological risks associated with the ultimate construction of a retrofit MHD facility or a commercial MHD power plant.

Moreover, measurements of selected parameters, coupled with empirj.cal correlations or an accurate model, can contribute significantly to improved control strategies and the selection of control instrumentation. The direct measurement of a particularly useful parameter for system control may be very difficult, if not impossible. However, another parameter which can be correlated to the parameter of interest may be much easier to measure. The application of advanced instrumentation promises to produce fundamental 
advances in this area. This type of information will be very important in the selection of control inst rumentation for a commercial MHD power plant.

MHD flows represent possibly the most severe environment encountered by gasdynamic diagnostics. Special state-of-the-art techniques and instrumentation systems are required to monitor and collect data for MHD component systems. In addition, these systems are operating under severe environmental and magnetic field conditions. The Diagnostic Instrumentation and Analysis Laboratory at Mississippi State University is developing and applying advanced optical diagnostic techniques and instrumentation systems which provide nonintrusive, remote, real-time measurements and are designed to operate successfully in the industrial-j.ike environment of large-scale facilities. Such diagnostic instrumentation can provide the information required to more clearly characterize the various processes involved in the ash/seed-laden gas stream of the coal-fired MHD flow. These systems will provide performance monitors giving real-time indications of

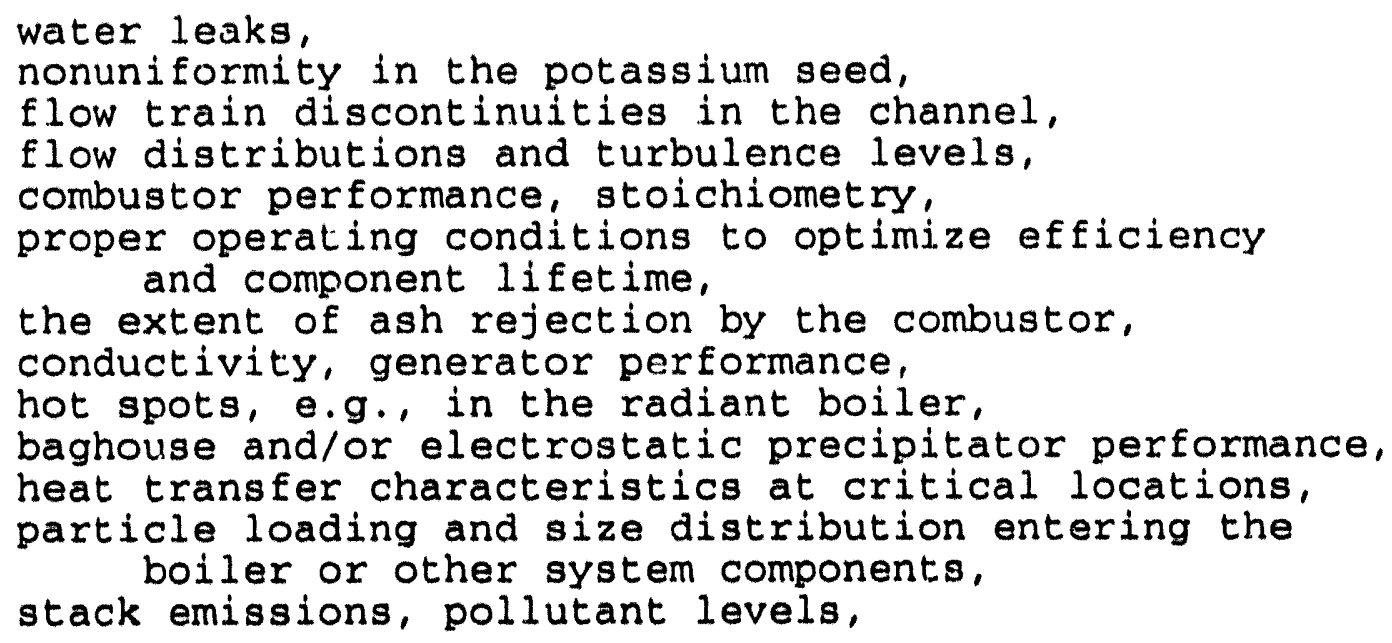

and will, therefore, further reduce the technical and financial risks associated with scale-up to the retrofit size integrated MHD steam plant or to a commercial size plant.

The computer-controlled, nonintrusive, advanced optical diagnostic instrumentation systems that will be used to determine these parameters are listed in the next section along with the salient features of the systems. Direct instrumentation support and measurements will be provided to the various DOE MHD test facilities. The amount of direct diagnostic support to the MHD engineering development test facilities will be as directed by DOE.

A number of the diagnostic systems which are fully developed will be used for field measurements at the HRSR and MHD power train Eacilities. Additional diagnostic systems previously developed are being constructed or modified to provide field-use instruments particularly for the MHD power train. Field tests for system 
refinements of these instruments will be conducted on the DIAL test stand and th various DOE MHD test facilities before proceeding with field measurements.

Some additional modifications are planned for existing instrumentation systems to expand their capabilities and range. A few additional diagnostic systems requiring only limited equipment are being developed where the method used can provide the basis for a simplified instrumentation system for MHD plant control or component monitoring. In most cases, these systems will share equipment with other existing systems.

DIAL has constructed a test stand that can simulate the gas-slagseed stream composition, temperature, and metal/fireside environmental conditions for the radiant furnace, superheater, and other MHD system components. The computer-controlled diagnostic instruments being developed are evaluated and tested on this test stand. Measurements conducted on the test stand also provide useful data for the national MHD program. 
In order to meet the overall contract objectives, the scope of work to be performed is outlined by the following tasks.

\section{Task 1. Diagnostic Instrument Development}

R. L. Cook, Section Manager

The following computer-controlled, optical diagnostic instrumentation is being developed for support of the MHD component engineering development. Objectives for the specific instrumentation systems follow.

\section{A Coherent Ant1-stokes Raman Spectroscopy System (CARS)}

(local gas temperature and species concentration, temperature and concentration profiles)

The CARS system is a laser-based, nonlinear, optical technique being developed to provide temperature and species concentration measurements with spatial and temporal resolution. Of the many laser-based techniques, CARS is the best suited for thermometry in high-interference environments because of its coherent, laser-like signal character and high signal conversion efficiency. To obtain a CARS spectrum, two narrow band lasers at pump frequency $\omega_{1}$ derived from the pump laser and one broadband dye laser at Stokes frequency $\omega_{2}$, are phase-matched and focused in the gas stream thereby generating, through the third order susceptibility of the medium, a spectrum at anti-stokes frequency $\omega_{3}$ $=2 \omega_{1}-\omega_{2}$. The CARS spectrum of a species le.g. nitrogen) can be sensitive to both gas temperature and species concentration.

The mobile CARS instrument is ready for field tests. Based on these tests, a few minor modifications may be required. Field measurements are planned throughout the contract period at both CFFF and CDIF if requested. Initially, point temperatures and temperature profiles from $\mathrm{N}_{2}$ CARS spectra will be measured. Work on improving the capabilities of the present CARS system will also continue. This will include automation of tre mobile CARS system. In particular, the CARS signal is focused to a 200- $\mu \mathrm{m}$ core diameter, 0.12 numerical aperture optical fiber with an achromatic lens, and is piped to the instrumentation trailer from the test environment. This coupling is very critical and needs to be remotely-controlled. In addition to temperature measurements, field measurements of species concentration will also be made. For example, temperature and Co concentration can be measured simultaneously using the multiplexed CARS spectra of $\mathrm{N}_{2}$ and $\mathrm{CO}$. The combined $\mathrm{N}_{2}-\mathrm{CO}$ CARS spectrum is then fit to a computersimulated CARS model to extract the temperature and co concentration. 
Work will continue on simultaneous $\mathrm{N}_{2}-\mathrm{CO}$ CARS to determine the detection limits of this technique for $\mathrm{CO}$ concentration measurement in $a$ particle-loaded gas stream.

Likewise, simultaneous $\mathrm{CO}_{2}, \mathrm{H}_{2}$, and $\mathrm{O}_{2}$ concentration measurements in an MHD gas stream can supply the stoichiometry every one to two minutes, which will enable one to monitor the performance of the combustor in real-time. The Raman resonant frequencies of $\mathrm{CO}_{2}, \mathrm{H}_{2}$, and $\mathrm{O}_{2}$ differ less than $200 \mathrm{~cm}^{-1}$ and can be assessed simultaneously with a single dye laser. Therefore, temperature and the $\mathrm{CO}_{2}, \mathrm{H}_{2}$, and $\mathrm{O}_{2}$ concentrations can be extracted from the simultaneous $\mathrm{CO}_{2}, \mathrm{H}_{2}$, and $\mathrm{O}_{2}$ CARS spectrum. A computer model will be developed and tested to enable the determination of the simultaneous temperature and $\mathrm{CO}_{2}$, $\mathrm{H}_{2}$, and $\mathrm{O}_{2}$ concentrations.

Particle-induced laser breakdown is known to produce a nonresonant CARS component which can affect the CARS measurement in a coal-fired flow. One way to alleviate this problem is to use a two-wavelength dye laser CARS configuration to extract the temperature. This technique also produces a signal which is 20 times stronger than that of broadband CARS at the same laser power. This and other ways to reduce the effects of particles will be studied.

\section{B Particle size Distribution System (PSD)}

(particle size distribution)

The PSD system uses optical, in-situ, scattering methods for measurement of particle size distribution. The three-beam, two-color particle size measurement system is designed to measure particles at slow velocity using a singleparticle counting method, while an ensemble averaging technique is used for high velocity flows. The system uses the output (green and blue) from an argon ion laser. The green beam is focused on the central axis and the blue beam is divided into two equal intensity beams which are focused and crossed inside the green measurement volume, producing an interference fringe pattern. The light scattered from these beams by a particle is processed to extract the particle size.

A particle passing through a focused laser beam sample volume generates a Gaussian-shaped scattering signal. The peak amplitude, detected at small angles in the near-forward scatter direction, is essentially a monotonic function of particle size and virtually independent of the particle refractive index and shape. The scattering signature is, however, dependent on the local sample volume intensity and, hence, the particle trajectory through the sample volume. Two techniques are presently being used to measure particle size -- the single particle counter (SPC) for low velocity flows and the ensemble 
averaging method (EAM) for high velocity flows. In the latter instrument, the small-angle, near-forward scatter (SANFS) signals of the green beam are measured. To eliminate the nonuniformity of response within the sample volume, the measurement volume intensity variation is measured. With this response function, a mathematical inversion technique (deconvolution) is used to extract the particle size distribution from the distribution of SANFS signal amplitudes.

In the case of the SPC instrument, two modes of operation are available - - the ripple-validated small-angle, near-forward scatter (RVSANFS) and the ripple deconvolution method (RDM). To reduce the trajectory ambiguity in the RVSANFS method, the single particle scattering signal from the central green beam is used to measure large particles $(2-15 \mu \mathrm{m})$ with the ripple signal from the crossed blue beams used to validate the trajectory of the large particles and, hence, discriminate particles not near the central region of the green measurement volume.

On the other hand, for the RDM the amplitude of the ripple signal from the crossed blue beams is used to size particles smaller than $2 \mu \mathrm{m}$. In particular, the visibility parameter, obtained from the ripple and pedestal signal, is used to reject data from large particles, and the deconvolution method is applied to the scattering signals from the blue beams to remove the ambiguity caused by the trajectory dependence.

Expected activities include laboratory experimentation, operation on the MSU test stand, and operation in the field. Laboratory experimentation will be related to development of the EAM instrument and continual upgrading of the SPC instrument. It will also include development of calibration techniques and the production and evaluation of aerosols. Operation on the MSU test stand will primarily be done for development of the EAM instrument and development of techniques to use physical sampling probes. Operation in the field will involve the SPC instrument until the EAM instrument is refined for field operation.

The overall objective is to improve the capability for measurement of particle size distributions by providing several alternate approaches that are feasible in various situations. Realization of this objective requires continual efforts to establish credibility that instruments are accurate and measurements are meaningful. This can only be achieved by continual attention to calibration methods and uses of alternate measurements, where possible, to supply corroborative data.

The particular objectives for the SPC are to finish construction of the system, to prove operation of the system in the field, and to refine the system for convenience in use and performance. Receiving fibers will be added to reduce the susceptibility to noise. Data will also be gathered for comparison of different modes of operation in 
the field environment; and, field measurements, to characterize the downstream components at the CFFF, will be conducted.

The specific objectives for the EAM are to prove the feasibility of the concept through experimental tests and incorporate this method into the field instrument. This will require continued theoretical and computational efforts to evaluate the parameters for the data reduction model; preliminary work on this is complete. Refinements will be needed as soon as the work is far enough along to justify them; these include the effects of lens aberrations, which will also require some experimental investigation.

Efforts will also begin on development of an cyperimental configuration for particle generation and laboratory measurements. Experiments will be conducted as soon as feasible on the test stand and, concurrently, field tests of the method will be made to define a suitable instrument package.

\section{C Potaenium smiesion/Abeorption syetem (PE/As)}

(time-resolved temperature, $K$-atom density, electron density)

The PE/AS system will rapidly measure (order of milliseconds) the average channel temperature by the line reversal technique, provide the average neutral potassium number density from lineshape information, and provide the average channel electron number density using the Saha equation assuming thermodynamic equilibrium.

This system has been field tested and is presently being used to provide time-resolved temperature and potassium number density measurements in support of the national MHD effort. Some software enhancement of the instrument is planned; however, the major issue to be resolved is the overestimation of the potassium number density. This is particularly important for wide gas st.reams and is believed to be caused by the line profile deviating from a Voigt shape in the far wings. Work to resolve this problem will continue.

\section{D Intrue1ve Mult1-Probe system (IMPS)}

(optical temperature probes -- wall and gas temperature)

The IMPS system has been developed to position various sensors at a precise location in a combustion gas stream for precise increments of time. It is completely computer-controlled and may be operated to position the probe and also to acquire the data. Optical sensors, as well as conventional sensors, can be used with this probe insertion system; however, its main use is with techniques where the probe will spend a very short period of time in the gas stream. Such a system interfaced with an optical 
technique can provide measurement capabilities in regions where, because of path length, optical measurements would not be possible.

Development and field testing of one viable intrusive sensor has been completed for the measurement of MHD interior wall surface temperatures. This sensor is capable of measuring surface temperatures in the range of 500 to $2000 \mathrm{C}$. Field test:s have been conducted at the DOE/CFFF by measuring the front surface temperatures of the superheater tubes during several test runs; the interior wall surface temperature of the furnace has also been measured.

The development of an intrusive sodium line reversal (SLR) sensor, to be used with the multi-probe systems for measuring local gas stream temperatures, is about 60 percent complece. This system uses an intrusive miniature optics system and the SLR principle to make spatially-resolved gas stream temperature measurements. The SLR sensor will provide gas stream temperature neasurements from 1700 to approximately $2500 \mathrm{~K}$.

Because surface temperature measurements would usually be required at distances greater than five feet in the MHD power system, on optic system is being developed to add to the existing lightpipe sensor to provide greater intrusive distances. In general, intrusive distances much greater than five feet are not possible with this sensor when accessing surfaces through the standard four-inch ports. This optics/lightpipe sensor system will provide added flexibility and a useful monitor for the larger-scale MHD development systems.

With the equipment on hand, the possibility of developing an intrusive, two-sensor system for measuring gas stream temperatures and wall surface temperatures appears to be very viable. This system would provide measurements of gas stream and wall surface temperatures in the range of 500 to $2000 \mathrm{C}$ and would be especially important for surface and gas temperature measurements in the region of the superheater tubes in large-scale MHD development systems.

\section{E Faraday Rotation Syetem (FRS)}

(electron deisity to infer conductivity)

The FRS system will provide real-time electron density measurements averaged across an MHD channel. The electrical conductivity scales very nearly linearly with the electron density. The technique is based on the Faraday effect. Linearly polarized light may be decomposed into right $(+)$ and left $(-)$ circularly polarized waves. Since the absorption coefficients and refractive index are different for right and left polarization, the amplitude and relative phase of the polarized waves are affected on passing 
through a plasma along a uniform magnetic field. Measurement of the rotation of the polarization of a beam of linearly polarized light after passing through a medium (plasma) in the direction of an applied magnetic field determines the electron number density. The system uses radiation in the far infrared derived from a $\mathrm{CO}_{2}-$ pumped far infrared laser.

This system will provide, directly, the electron density and conductivity of the MHD channel which is essential to the characterization of the power train performance. Most of the major equipment for the system has been obtained. The system assembly for electron density and conductivity measurements on a laboratory plasma are basically complete. Electron mobility modeling and measurements will be addressed and system refinements, such as waveguides and detector vibration isolation for field tests, will follow. Field measurements could be made at the DOE/CDIF if optical access through the channel side walls is made available.

\section{F Mult1-Purpose Imaging syetem (MPIS) \\ (K-atom density, pressure profile)}

The MPIS system is a laser-excited imaging system suitable for spatially-resolved optical diagnostics. The system is based on the phenomena of laser-induced fluorescence (LIF). Here an atomic or molecular species is raised to an excited electronic state by absorption of laser radiation. The emitted radiation when the species returns to the ground state is termed fluorescence. The instrument consists of a laser whose beam is expanded with cylindrical optics into a wide, thin sheet that is directed through the region of interest. A camera lens is then used to focus light emitted by this region onto a charge injection detector, the signal fro.n which is processed by a computer to produce a two dimensional image of the probed region. The versatility of the system comes from the ability to select both the excitation and observation wavelengths to determine various parameters of interest, such as the concentration mapping of selected atomic and molecular species.

The MPIS system is an instrument currently in development, which will allow measurements of species ( $\mathrm{K}, \mathrm{Na}, \mathrm{OH})$ concentration profiles in harsh combustion environments. The excitation intensity must be tuned to a resonance absorption with sufficient power that the fluorescence intensity is propcrtional to species concentration. In addition, measurements of number density and pressure profiles are possible, as well as temperature profiles using two-wavelength, 
excited-state fluorescence measurements. In the case of pressure determinations, the excitation intensity must be above that required for.level saturation; then the fluorescence intensity is proportional to the pressure.

Previous work has involved the construction of a laboratory-scale system and subsequent measurements of sodium concentration images and potassium LIF. The latter measurements have been complicated by collisional quenching, a process whereby the excited states decay non-radiatively. For example, $K$ LIF at $404.5 \mathrm{~nm}$ has been observed but at a significantly reduced quantum efficiency as compare to Na. Saturation of the $404.5-\mathrm{nm} \mathrm{K}$ line is not possible without increasing the intensity level of the incident excitation wavelength. Addition of a wavelength extension unit (WEX) to the current optical train is planned since this will drastically increase the incident laser power by mixing the 1.06- $\mathrm{m}$ fundamental of the Nd: YAG laser with the low efficiency output of the dye laser in an appropriated crystal. Concentration measurements on $K$ can then proceed. The determination of pressure profiles will begin with the construction of a variable pressure burner which will permit measurements as a function of known pressure. Laser-induced fluorescence measurements will then be performed to determine the limitations of the technique as applied to harsh environments.

Determination of the fluorescence at two wavelengths will allow the measurement of the populations of the excited species, which, in turn, can be used to determine spatial temperature profiles of a region. In order to accomplish this task, an additional detector (camera) will be incorporated with an extended blue wavelength response. This detector will also permit the evaluation of $\mathrm{OH}$ fluorescence. Measurements on the MHD power train will require optical access. Access can be expected to be a problem, especially for image capture; therefore, a flexible, image transmitting fiber bundle will be added allowing the fluorescent or scattered laser light image to be routed to the camera which will be located away from the measurement penetration and clear of the upstream plumbing and structure.

The limitations and attributes of the system with respect to species concentration, pressure gradients, two wavelength temperature, and number density measurements will be established and concurrently field tests with the system will be conducted. Results from these initial tests will be used to construct a stable, reliable field version of the instrument.

\subsection{Differential Abeorption Laser spectromcopy syetem (DALAS) \\ (species concentration, $\mathrm{SO}_{2}, \mathrm{NO}_{2}, \mathrm{NO}, \mathrm{H}_{2} \mathrm{O}, \mathrm{OH}$ )}

The DALAS system is a general purpose, nonintrusive instrument for measuring time-resolved, line-of-sight average concentrations of atomic and molecular species. The system uses a twowavelength dye laser and measures the extinction 
of the two wavelengths through the gas stream. One wavelength is on and the other off resonance of the species of interest, thereby eliminating particle absorption and scattering effects.

A general purpose system for measuring average concentrations of individual species $\left(\mathrm{H}_{2} \mathrm{O}, \mathrm{SO}_{2}, \mathrm{NO}_{2}, \mathrm{NO}, \mathrm{OH}\right)$ is desirable to complement the CARS system which does not measure the concentrations of these species. The DALAS system is a general purpose technique which can, in principle, be applied to any atomic or molecular species; and can be brought on line by additions to the existing mobile CARS instrumentation. It can also provide time-resolved concentration measurements when concentration fluctuations are of interest. DALAS uses methodology and technology developed over the past decade for differential absorption lidar, a mobile, laser-based remote sensing technique for measuring the concentrations of pollutants in the atmosphere. To implement the technique, frequency doubling crystals, a detector, two boxcar averagers, and a control computer are required.

A DALAS experiment is performed by comparing the transmission of two wavelengths through the sample. One wavelength corresponds to a strong absorption of the species of interest. The other wavelength is a nearby wavelength that the species does not (or only weakly) absorbs. Taking the ratio of the transmitted intensities of the two wavelengths cancels out background effects, such as light scattering due to particulates, that are not associated with absorption by the species. If the absorption coefficient of the species is accurately known, or appropriate calibration experiments have been made, then the absolute concentration of the species can be determined.

The DALAS apparatus will use a single laser system to generate both wavelengths. An alternating two-wavelength dye laser pumped by the CARS Nd:YAG laser $(10 \mathrm{~Hz})$ will generate on alternate laser pulses the on-resonance wavelength $(5 \mathrm{~Hz})$ and the off-resonance wavelength $(5 \mathrm{~Hz})$. In particular, a rotating, rectangular optical block is used to refract the dye laser beam to independent wavelength selection systems, thereby generating two closely spaced wavelengths. The successful operation of this dye laser is not sensitive to the alignment of the dye laser beam and the block; this ruggedness is important for field measurements. The visible dye laser beams can be frequency doubled into the ultraviolet by sending them through two frequency doubling crystals - - one crystal for each wavelength. Both wavelengths follow the same path through the plasma onto a single photodiode. The output of the photodiode for on-resonance laser pulses is fed to one boxcar averager; the output of the photodiode for offresonance pulses is fed to a second boxcar averager. The ratio of the intensity outputs of the boxcar averagers enables calculation of the concentration of the species.

DALAS can, in principle, be applied to any atomic or molecular species. The focus will be on measuring the concentrations of $\mathrm{H}_{2} \mathrm{O}$, $\mathrm{SO}_{2}, \mathrm{NO}_{2}, \mathrm{NO}$, and $\mathrm{OH}$ because the concentrations of these species, 
though important, are not measured by the CARS system. OH and $\mathrm{H}_{2} \mathrm{O}$ are of interest because they decrease flame conductivity, and hence, adversely effect the performance of the MHD power train system. $\mathrm{SO}_{2}$, $\mathrm{NO}_{2}$ and NO are of interest because they are pollutants and thus their environmental impact is important.

The methodology for observing and recording DALAS signals will be validated. The instrumental operating parameters will be optimized for $\mathrm{H}_{2} \mathrm{O}, \mathrm{SO}_{2}, \mathrm{NO}_{2}, \mathrm{OH}$ and $\mathrm{NO}$ in bench-top flames and DIAL's MHD test stand. The system will be field tested prior to field measurements.

\section{H Lacer Optogalvanio spectroscopy syotem (LOCS)}

(average gas temperature, qualitative species identification)

The LOGS system is a general purpose instrument for measuring line-of-sight average temperatures and will provide qualitative identification of various atomic and molecular species. The system uses a tungsten electrode, which is inserted into the gas stream and used to monitor changes in conductivity as a dye laser is tuned into resonance with a particular species.

A general purpose system for measuring average temperature is desirable, especially one capable of working even when high particulate flow severely limits transmission of optical beams across the MHD flow. LOGS is such a general purpose technique and can be brought on line by additions to existing instrumentation. Essentially, a frequency doubling unit with automatic scanning capability is all that is required. Because LOGS uses electrical rather than optical detection, the technique alleviates problems associated with monitoring small absorptions or weak fluorescence in the presence of a strong optical background signal or large path lengths. Hence, LOGS can identify species present and characterize their temperature under conditions where techniques using optical detection fail. Moreover, only optical access on one side of the gas stream is required for this system.

In LOGS a pulsed dye laser is tuned into resonance with a transition of a species in a plasma; the excited state concentration of that species then temporarily increases. Because the energy necessary for ionization is less for an excited electronic state than for the ground state, the rate of ionization temporarily increases. This process can be monitored as a transient (10 - $5 \mathrm{sec})$ voltage change (in lab flames, typically hundredths of a volt) if a high voltage (typically $+400 \mathrm{~V}$ ) electrode (e.g. tungsten, MP $3410 \mathrm{C}$ ) is inserted into the plasma. Although most of the research on LOGS has concentrated on atomic species, 25 molecular species (such as $\mathrm{NO}_{2}$, $\mathrm{HCO}, \mathrm{N}_{2}, \mathrm{CO}, \mathrm{CO}_{2}$, and $\mathrm{H}_{2}$ ) have been studied to date. Efforts will concentrate on molecular species present in combustion environments, in particular, on $\mathrm{OH}, \mathrm{C}_{2}$, NO, and $\mathrm{CO}$. By scanning the wavelength of a tunable dye laser and recording the optogalvanic signal as a function 
of laser wavelength, the optogalvanic spectrum (which is analogous to an absorption spectrum) is obtained. The temperature of the species can be ascertained by the standard technique of ratioing the intensities of different transitions and taking into account their different transition probabilities.

The methodology for observing and recording LOGS signals of atomic and molecular species will be validated in bench-top flames and DIAL's MHD test stand, and the instrumental operating parameters will be optimized. Effects of electrode aging, of electrode size, and of particles on the LOGS signal intensity will be studied in bench-top tests and test stand experiments. The precision of the temperature measurements in MHD environmentr will be established by comparing temperatures determined by LOGS with that obtained from CARS. Field tests and subsequently field measurements will be carried out during this work period.

\section{I Crose Correlation syotem (CCs) (flow velocity)}

The CCS system will measure the flow velocity nonint rusively with only limited optical access. The technique involves measuring the fluctuations in gas luminosity, e.g., at two spatially separated locations. The cross correlation function of these signals gives the time interval between which the signal and a time displaced version of itself correlates.

A simple, rugged, accurate, and nonintrusive system to measure the gas flow velocity would be a particularly valuable device to help monitor the MHD power train. The cross correlation technique can provide such an instrument and can be used to find the mean velocity of the gas flow. The method can find application where only limited access to the gas stream is available. The technique is based on the naturally occurring fluctuations in, e.g., species concentration, temperature, and particle concentration in a turbulent combustion environment. If a fluctuating variable is measured at two known locations -- one upstream and the other downstream -- then the time required for the fluctuations to travel from one location to another provides the flow velocity.

Preliminary work performed by DIAL indicates that the cross correlation method can be implemented using gas luminosity as the fluctuating variable. It is also believed that the correlation of signals obtained by measuring the extinction of laser light at two or more locations can provide the flow velocity. This method would allow velocity measurements where gas luminosity is weak. Other extensions of the basic concept, using intersecting beams, have the potential for measuring spatially-resolved velocity profiles. 
A cross correlation experiment is performed by using two identical optical systems for data collection, with one located upstream and the other downstream. Each optical system consist s of a focusing lens, a small monochromator, and a photomultiplier tube. The monochromators allow any wavelength of light from 200 to $800 \mathrm{~nm}$ to be selected. This spans the range from the ultraviolet to visible to the near infrared. The electrical signals from the photomultiplier tubes are amplified, low pass filtered, and sampled (both signals simultaneously) by an analog-to-digital (A/D) converter connected to a computer.

The data analysis consists of computing the cross correlation function of the two digitized signals. If the signals are correlated, i.e., only shifted in time by an amount $\tau$, then the cross correlation function will show a peak at $\tau$. In this way, by computing the cross correlation function of the two photomultiplier signals, the time delay required for intensity fluctuations to propagate downstream can be found and thus the flow velocity can be determined.

Implementing the system for measurements on MHD channels with large flow velocities will reguire a fast $A / D$ converter, and continuous operation will require large storage capacity and a fast processor to reduce the data as quickly as possible. 
Task 2. Test stand Operatione

J. A. Etheridge, Section Manager

DIAL has a computer-controlled, combustion test stand to simulate the combustion and thermal parameters present at various locations in a fossil-fueled MHD combustion system. Its versatility allows it to be used to simulate any type of combustion condition and effluent gas stream.

DIAL's MHD/HRSR simulation test stand will be used for support of diagnostic instrumentation development, shake-down, and evaluation. The test stand has recently been modified to better simulate the MHD gas stream environment. This will further ald in the evaluation of the instruments before they are taken to DOE's MHD engineering development test facilities. In particular, the test stand has been modified to burn a fuel oil/coal slurry that will more accurately simulate a coal fuel MHD combustor. Provisions for an increased flow rate of fuel/air mixture of approximately $700 \mathrm{lb} / \mathrm{hr}$ have been made. The test tand control and data acquisition computer has also been replaced with a new system to enhance data collection and control, as well as provide much needed memory and disk space.

As the need arises, the test stand may also be used for gathering data systematically, under controlled conditions, to provide validation data for analytical models. 
Task 3. Teobnioal support for the National whD program

R. D. Benton, Section Manager

The primary objective of this task is to provide diagnostic measurements and support to the national MHD program. The task includes attendance at contractor review meetings and contributions to technical progress reports. It also includes the preparation of a topical report for each diagnostic system at the time when it is available for field measurements. Objectives for this task are described below.

\section{A Fleld Moasuremente}

\section{A.1 Bodium IIne Reverual gyetem (ELR) (average gas temperature)}

The SLR system measures the temperature of the central region of the gas stream. The technique uses a calibrated light source and is based on making a series of intensity measurements on the wing of one of the sodium D-lines.

This system is field ready and has been used at various MHD facilities in. support of the national program. No additional modifications are planned except to maintain the system field ready.

\section{A.2 mult1-Color pyromoter (MCP) \\ (wall temperature and emissivity)}

The MCP system measures the wall temperature and emissivity of the wall surface. The technique is based on Planck's radiation law and requires measurement of the radiation intensity from the wall surface at two or more wavelengths, assuming the presence of a graybody radiator.

This system is field ready and has been used at various MHD facilities in support of the national program. No additional modifications are planned except to maintain the system field ready.

\section{A.3 Two-Color Laser Tranemlesomoter (TCLT)}

(average particle size, particle number density)

The TCLT system measures the average particle sizo and particle loading in the gas stream. The technique is based on measuring the extinction of laser light at two wavelengths (e.g.., the infrared and visible regions), and knowledge of the refraction index of the particles.

This system is field ready and the TCLT units will continue the determination of average particle diameters and loadings at various 
DOE MHD facilities. Previous work has concerned the study of $\mathrm{K}_{2} \mathrm{SO}_{4}$ nucleation and real-time evaluation of the performance of the CFFF electrostatic precipitator and baghouse. During this work period, characterization of the particle size at upstream locations will be carried out. These measurements will concern particulate behavior and ash carry-over in the upstream portions of the facility, and have implications on slag/seed interactions and thus seed recovery. In addition, ongoing measurements concerning the CFFF particulate retention components will continue to evaluate the effects of the ESP operating characteristics on particulate properties.

Initial TCLT measurements at the CFFF diffuser exit and at various levels of the radiant furnace have indicated that the average particle diameters at some locations exceed the current measurement range $(0.3-$

$4 \mathrm{\mu m}$ ) of the instrument. Somewhat larger diameters are expected at upstream locations when compared to the cooler sections of the steam bottoming plant. In regions of high turbulence such as channels, slag can become re-entrained; in addition, fly ash (not $\mathrm{K}_{2} \mathrm{SO}_{4}$ ) will nucleate at high temperatures. Knowledge of the average particle diameters and loadings would be expected to aid in calculations of heat transfer, erosion, and generator performance. Extension of the particle size range would increase the accuracy of the system and allow direct measurements at upstream locations.

In order to increase the upper particle size limit of the TCLT, an isotopic $\mathrm{CO}_{2}$ laser and accessories will be added. The use of an isotopic lasing medium such as

$$
\mathrm{C}^{12} \mathrm{O}_{2}^{10}
$$

will permit operation at $>9 \mu \mathrm{m}$ and will effectively avoid attenuation of the beam by the natural

$$
\mathrm{C}^{12} \mathrm{O}_{2}^{16}
$$

present as a combustion byproduct. Incorporation of the isotopic $\mathrm{CO}_{2}$ laser into the TCLT optical configuration will increase the particle diameter measurement range from $(0.3-4 \mu \mathrm{m})$ to $(0.3-2 \mu \mathrm{m})$.

The current size of the TCLT optical breadboerd is approximately $29 " \times 80 "$ and weighs about 100 lbs. It should be possible, by incorporating fiber optics, to route the laser beams from one breadboard unit to multiple port locations using both visible and infrared fibers along with appropriate connectors and optics. In this way, measurements of average particle size and loadings could be made at different locations from the centrally located breadboard. At present, the optical breadboard must remain in close proximity to 
the penetration position and each measurement location must have one breadboard. The incorporation of fiber optics would result in increased flexibility and, moreover, the lasers, etc., could be conveniently removed from the magnetic field regions present at the CDIF.

\section{A.4 Laser Doppler Veloclmeter system (LDV)}

(local velocity, velocity profile and turbulence level)

The LDV system measures the gas velocity and turbulence level at a given point in the gas stream. The technique is based on measurement of the modulation frequency of the scattered light from a particle traversing a measurement volume which is formed by intersection of two focused laser beams. A one-color and a two-color system are available that measure one and two components of the velocity, respectively. A velocity profile can be obtained and both forward and back scatter measurements can be made.

The ILDV system is field ready and has provided a number of useful velocity flow measurements in support of the national MHD program. To improve the operation and information derivable from the system, a second pair of transmitting and receiving optical fibers will be incorporated in the LDV optical train. This will allow two colors (green and blue) of incident laser light to be simultaneously transmitted to the measurement site and thus, two components (axial and radiall of particle velocity can be determined. The use of optical fibers is absolutely mandatory for field measurements, especially for difficult measurement sites such as the combustor exit at the CDIF.

To complete the two-color optical fiber LDV system, a second signal processor (burst spectrum analyzer) is required. Two signal processors are required for simultaneous measurement of two velocity components of a particle. During previous field measurements at CFFF and TRW, two-component (nonsimultaneous) velocity measurements were made; but it was possible to do so only becaus's physical access to the measurement site was allowed during the test. Protocol at the CDIF facility strictly forbids such access during a test, so a second signal processor will be mandatory for two-component measurements.

Plans also include incorporating smaller stepper motors in both the forward and backscatter traverses so only one power supply will be required to drive both. A remote controlled focusing device for the forward scatter detection system will also be added. This will allow optical alignment to be maintained during traverse of the forward optics for velocity profile measurements.

Recent experience at CDIF proved that Dorpler frequencies in the range of $50-70 \mathrm{MHz}$ are to be expected for such flows. The only way to be confident that a proper LDV signal is being processed is 
to capture the transient Doppler burst using a storage oscilloscope. It is desirable, therefore, to add a high speed digital storage oscilloscope to use in such applications.

\section{A.5 Potaseium miselon/Absoxption system (PE/As)}

(time-resolved temperature and $\mathrm{K}$-number density)

The PE/AS system rapidly measures (order of milliseconds) the average channel temperature by the line reversal technique.

This system has been field tested and is presently being used to provide time-resolved temperature measurements in support of the national MHD effort. Some software enhancement of the instrument is planned.

\section{A.6 Gas Analyois syotem (GAs)}

(gas composition, e.g., $\mathrm{CO}, \mathrm{CO}_{2}, \mathrm{NO}$, etc.)

The GAS system is capable of analyzing gases from fossil fuel combustion processes including $\mathrm{NO}_{x}$, $\mathrm{CO}_{x}, \mathrm{SO}_{2}, \mathrm{O}_{2}$, and combustibles. The system requires continuous extraction of a gas sample for analysis. The gas chromatograph (GC) can detect $\mathrm{CO}, \mathrm{CO}_{2}, \mathrm{~N}_{2}$, and $\mathrm{O}_{2}$ using a thermal conductivity detector. Other gases of interest can also be monitored with the GC by selection of the appropriate column. Samples to be analyzed by the GC are collected and stored in glass sample bulbs for later analysis.

This system is field ready and no additional modifications are planned except to maintain the system field ready.

\section{B Fleld Tests/Instrument Modifications}

\section{B.1 Coherent Ant1-stoken Raman spectroscopy Syøtem (CARS)}

(local gas temperature and species concentration, temperature and concentration profiles)

The CARS system is a laser-based, nonlinear, optical technique being developed to provide temperature and species concentration measurements with spatial and temporal resolution. Of the many laser-based techniques, CARS is the best suited for thermometry in high-interference environments because of its coherent, laser-like signal character and high signal conversion efficiency. To obtain a CARS spectrum, two narrow band lasers at pump frequency $\omega_{1}$ derived from the pump laser and one broadband dye laser at stokes frequency $\omega_{2}$, are phase-matched and 
focused in the gas stream thereby generating, through the third order susceptibility of the medium, a spectrum at anti-stokes frequency $\omega_{3}$ $=2 \omega_{1}-\omega_{2}$. The CARS spectrum of a species (e.g. nitrogen) can be sensitive to both gas temperature and species concentration.

The mobile CARS instrument is ready for field tests. Based on these tests, a few minor modifications may be required. Field measurements are planned throughout the contract period at both CFFF and CDIF if requested. Initially, point temperatures and temperature profiles from $\mathrm{N}_{2}$ CARS spectra will be measured. Work on improving the capabilities of the present CARS system will also continue. This will include automation of the mobile CARS system. In particular,

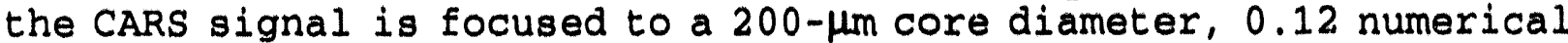
aperture optical fiber with an achromatic lens, and is piped to the instrumentation trailer from the test environment. This coupling is very critical and needs to be remotely-controlled. In addition to temperature measurements, field measurements of species concentration will also be made.

\section{B.2 Partiole size Distribution syotem (PRD)}

(particle size distribution)

The PSD system uses optical, in-situ, scattering methods for measurement of particle size distribution. The three-beam, two-color particle size measurement system is designed to measure particles at slow velocity using a singleparticle counting method, while an ensemble averaging technique is used for high velocity flows. The system uses the output (green and blue) from an argon ion laser. The green beam is focused on the central axis and the blue beam is divided into two equal intensity beams which are focused and crossed inside the green measurement volume, producing an interference fringe pattern. The light scattered from these beams by a particle is processed to extract the particle size.

Operation in the field will involve the single particle counter (SPC) instrument until the ensemble averaging method (EAM) instrument is refined for field operation. The particular objectives for the SPC are to finish construction of the system, prove operation of the system in the field, and refine the system for convenience in use and performance. Receiving fibers will be added to reduce susceptibility to noise. Data will also be gathered for comparison of different modes of operation in the field environment and field measurements to characterize the downstream components at the CFFF will be conducted. 
The specific objectives for the ensemble averaging method (EAM) instrument are to prove the feasibility of the concept through experimental tests and incorporate this method into the field instrument. This will require continued theoretical and computational efforts to evaluate the parameters for the data reduction model. Preliminary work on this is finished. Refinements will be needed as soon as the work is far enough along to justify them; these include the effects of lens aberrations, which will also require some experimental investigation.

Efforts to develop an experimental configuration for particle generation and laboratory measurements will be initiated. Experiments will be conducted on the test stand as soon as feasible and, concurrently, field tests of the method will be used to define a suitable instrument package.

\section{B.3 Intrue1ve Mult1-Probe syetem (IMP8) (wall and gas temperature)}

An IMPS system has been developed to position various sensors at a precise location in a combustion gas stream for precise increments of time. It is completely computer-controlled and may be operated to position the probe and also acquire the data. Optical sensors as well as conventional sensors can be used with this probe insertion system; however, its main use is with techniques where the probe will spend a very short period of time in the gas stream. Such a system interfaced with an optical technique can provide measurement capabilities in regions where, because of path length, optical measurements would not be possible.

Development and field testing of one viable intrusive sensor has been completed for the measurement of'MHD interior wall surface temperatures. This sensor is capable of measuring surface temperatures in the range of 500 to $2000 \mathrm{C}$. Field tests have been conducted at DOE's CFFF by measuring the front surface temperatures of the superheater tubes during several runs of the facility; the interior wall surface temperature of the furnace has also been measured.

\section{B.4 Faraday Rotation syatem (FRs)}

(electron density to infer conductivity)

The FRS system will provide real-time electron density measurements averaged across an MHD channel. The electrical conductivity scales almost linearly with the electron density. The technique is based on the Faraday effect. Linearly polarized light may be decomposed into right $(+)$ and left $(-)$ circularly polarized 
waves. Since the absorption coefficients and refractive index are different for right and left polarization, the amplitude and relative phase of the polarized waves are affected on passing through a plasma along a uniform magnetic field. Measurement of the rotation of the polarization of a beam of linearly polarized light after passing through a medium (plasma) in the direction of an applied magnetic field determines the electron number density. The system uses radiation in the far infrared derived from a $\mathrm{CO}_{2}$ pumped far infrared laser.

The FRS will provide directly the electron density and conductivity of the MHD channel, which is essential to the characterization of the power train performance. Most of the major equipment for the system has been obtained. The system assembly for electron density and density measurements on a laboratory plasma are basically complete. Electron mobility modeling and measurements will be addressed. System refinements for field tests (such as waveguides and vibration isolation for detectors) will follow. Field measurements will be made at CDIF if optical access is available.

\section{C rield Operation/Developing syoteme}

\section{C.1 General puxpoee spectral scanning syetem (OPBs)}

(emission spectra from ultraviolet to near-infrared)

The GPSS system will detect emission from atomic and molecular species in the gas stream and provide an intensity versus wavelength record covering the ultraviolet to the near infrared. The system uses receiving optics and a computercontrolled monochromator equipped with a wideband detector.

Initial spectral emission measurements in the visible region at CDIF indicate it would be valuable to have a spectral scanning system covering the wavelength region from the ultraviolet to the near infrared. Building on existing equipment, construction of a GPSS system is planned. This system will provide a direct qualitative indication of many of the atomic and molecular species present in the gas stream. It would be particularly convenient for studying the MHD channel flow since only a very small optical fiber access hole would be needed. For instance, atomic lines $(\mathrm{N}, \mathrm{S}, \mathrm{C}, \mathrm{O}$, etc.) or diatomic lines ( $\mathrm{CO}, \mathrm{OH}, \mathrm{O}$, NO) could probably be detected at very high temperatures. These measurements would provide useful information for comparison with equilibrium calculations and possibly useful correlations on the operation of the MHD power train. 
3.C.2 Visible IR imienton 8pectroscopy syetem (VIs8)

(emission spectra from ultraviolet through near-infrared)

The VIES system will detect wavelength-resolved emission from the ultraviolet through the nearinfrared. Comparison of the resulting emission spectrum with the spectrum of an available, commercial blackbody radiation source will enable estimation of relative emissivity values. The system uses receiving optics and a computercontrolled monochromator equipped with broadband detectors.

In order to evaluate the HTAH ceramic for possible use in its combustor, the CFFF would benefit from knowledge of its relative emissivity values in their gas stream. Construction of a VIES system built mostly with available equipment is planned. This system will record the wavelength-resolved emission spectrum of the ceramic in the CFFF gas stream. Estimates of the relative emissivity values would be obtained from comparison of the emission spectrum with spectrum of an available, commercial blackbody radiation source. In addition, this system could be utilized to obtain the relative emissivity values of other substances, or to study the emission of atomic and molecular species present in high temperature MHD gas streams.

\section{C.3 IR Water Deteotor (IWD)}

Water absorbs infrared radiation at a number of wavelengths, but those located near 1.4, 1.9, and $2.7 \mu \mathrm{m}$ hold the greatest potential for diagnostic purposes in a combustion stream. The radiation emitted from the walls of a combustion facility provide sufficient intensities of infrared light in these regions to allow simple absorption measurements to be made at a single viewing port. The selection of the optimum region for making the necessary measurements depends upon factors such as the amount of water normally in the combustion stream, the minimum amount of excess water which must be detected, and the inherent absorption strengths of water at the wavelengths under consideration.

Experiments will be conducted to determine the feasibility of developing an infrared water detector instrument.

DIAL will supply mobile instrument laboratories with computercontrolled diagnostic instrumentation und trained operators for on-site measurements. Field measurements will be made at DOE's national MHD facilities on an as-needed basis. These mobile labs will be used to house the diagnostic equipment for transportation to, and for use at, a particular facility. The Airstream mobile instrument laboratory 
(MIL) has its own electric power source. Recently, an 18-wheeler type trailer has been modified to provide an advanced mobile instrument laboratory (AMIL) to supplement the capacity of the MIL which has been operational for a number of years. The AMIL is used for the advanced diagnostic systems, such as CARS, FRS, etc., and for simultaneous operation of a large number of DIAL instruments.

Both field laboratories have on-board computers for on-line data acquisition and control of the diagnostic equipment. The existing data analysis system, however, lacks the speed and capabilities necessary to provide quick, report quality feedback to the facility. To this end, modifications and additions will be made to the on-1ine data analysis system. The particular goals aro:

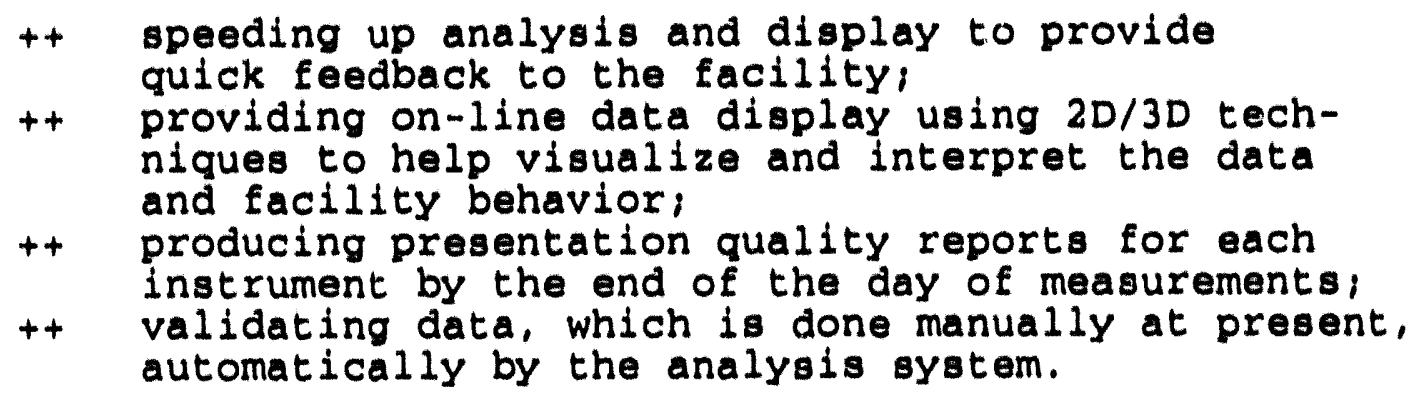

DIAL has started evaluation of the required advanced instrumentation to control a complete MHD system. As part of the support of the national MHD program, this effort will include evaluation of diagnostic systems for monitoring/controlling as well as evaluating the dynamic characteristics of the complete MHD system when the bottoming cycle is integrated with the topping cycle. Instrumentation will hence be selected to control the MHD power system under all perturbations. 


\section{Tack 4. Profeot knnagenont}

The objective of this task is to provide the required management for accomplishment of the profect objectives with the proposed resources management reporting as required by DOE Order $1332.1 \mathrm{~A}$. contract reporting requirements will be part of this task. 


\section{Taek 5. Technology Tranezer}

Technology transfer is a congressionally-mandated objective of the federal government. To ensure the maximum benefits for the Pittsburgh Energy Technology Center's (PETC), and subsequently DIAL's, investment in research and development, DIAL's personnel will cooperate with regional industries to demonstrate the technology for intrusive and nonintrusive diagnostic instrumentation developed for the characterization of MHD systems. Organizations which have already benefitted actively from this technology transfer are Dow Chemical USA, Dantec Electronics, NASA, and the stennis Space Center. However important, this task shall in no way interfere with the mainstream efforts of the MHD program. 


\section{DISCRIPTION OF PACILITIE}

The combustion test stand is a computer-controlled simulation test facility available for the combustion of fuel oll up to $800 \mathrm{lbm} / \mathrm{hr}$ of fuel and air. A system for using a coal slurry for fuel is presently under development. The air can be preheated to temperatures up to $1100 \mathrm{~K}(1520 \mathrm{~F})$ by electrical resistance heaters. Downstream of the combustor are refractory-1ined sections containing access ports on both sides and the top of each section.

The DIAL test facility has a Hewlett-Packard measurement and control system (HP- $1000 / A 400 \mathrm{mini}$ computer-based system) with real-time software, graphics, and extensive input-output (I/O) capability.

The microprocessor development laboratory has a ix PC's, two IBM PS/2-80's, and two Diversified Technology development aystems for developing software and $f$ irmware for special purpose microcomputers to be used in controlling diagnostic instruments, signal processing, and signal and data analysis. A variety of other PC' $B$ and microcomputers (at least twelve) are part of the field instruments and those under development.

Complete laser facilities are available, including YAG and dye lasers, spectrometers and photometers, fiber optics, and other equipment. Discharge lamps, power supplies, vacuum aystems, UV optics, monochromators, detectors, and processing electronics are also available. In addition, the laboratory has several bench-top laboratory burners controlled by precision gas handling systems.

The following facilities are available in DIAL: electronics shop, machine shop, instrument shop, and gas sampling and analysis system. The Department of Electrical Engineering at MSU has the facilities and staff for the design, development, and construction of hybrid integrated circuits and printed circuit boards.

Modeling and data analysis are done on the newer, more powerful PC's (PS/2 and 386 PC' $^{\prime}$ ) and the VAX 11/780 and VAXstation 3200 . Large scale analysis and modeling is required for various instruments including CARS, LDV, and PE/AS. Other instrument development and refinement projects also require continued modeling support in the areas of general combustion/heat transfer and gas flow modeling. 


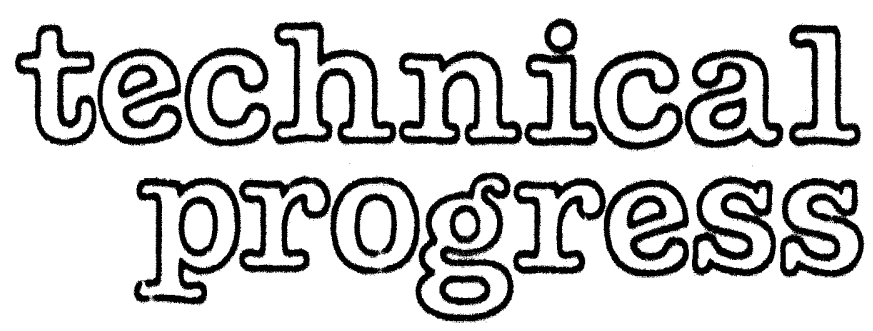


Task 1. Dlagnost Io Inotrument Davolopment

\section{A Cohorent Ant1-stokes Raman spoctropoopy syoten (CAng)}

$J$. P. Singh and F. Y. Yueh, Principal Investigators

\section{Mork Partormod}

Measurement of the temperature and temperature profile cont inued with the folded BOXCARS and collinear CARS geometries in a $\mathrm{CH}_{4} / \mathrm{al} r$ $t 1$ ame and in DIAL' MHD test tacility. Recent $1 y$, the problem of spatial averaging in CARS thermometry in a turbulent combust ion environment has gained much attention. 1.2 This problem will be more serious for a temperature measurement close to the boundary of the gas stream where the temperature gradient is generally very large. A comparative study was conducted of the temperature profile measurement with the various phase matching geometries, which will provide the necessary intormation for selecting a phase matching geometry for the application of the mobile CARS yystem to a coal-fired MHD combustor. This study is focused on collinear and BOXCARs measurements. The interred temperature error trom each technique was sudied both theoretically and experimentally.

The CARS temperature measurement error due to spatial averaging in a focal volume with a nonuni form temperature was first investigated by Boquilion, et al. The numerical study of the effect of spatial resolution in CARS thermometry in a turbulent tame was soon followed by shopherd, et al." These studies were performed for measurements with the BOXCARS phase matching geometry which provides the best spatial resolution among other phase matching techniques. To select a phase matching technique for tield use, aimplified theoretical modols were developed and used for studying the temperature measurement error. First, a bi-temperature distribution model was used for atudying the measuremont made in a turbulent environment. This type of analysis is helpful for understanding the possible temperature error in a practical environment.

When CARS measurements are made at a location which has a high temperature gradient and a turbulent gas stream, it is possible to extract two temperatures $\mathrm{from}$ a set of measurements due to fluctuation in the gas stream. Therefore, bimodal temperature studies presented here are very useful for evaluating the possible temperature error through a time-averaged spectrum taken in a turbulent medium with a significant temperature gradient. Boquillon, et al. " studied the blmodal temperature in detail.' They concluded that the inferred temperature error increases with the difference of the two temperatures involved.

A study was also conducted by DIAL on the bimodal temperature spectrum which concentrated on the fitting techniques used for this type of data. The test spectra were calculated by assuming the probed volume contains two different temperatures $\left(T_{1}=500 \mathrm{~K}\right.$ and $T_{2}=2200$ K). Two fitting techniques were tested. Each test spectrum was first 
fitted with the computer-simulated CARS temperature 1 ibrary to extract temperature, then the same spectrum was fitted by excluding some data points around the peak of the $\mathrm{N}_{2}$ cold band. Each fitted data point is weighted equally in the two fitting techniques. Figure 1.A.1 shows the fitting of a test spectrum. A ratio of the volume containing the cold gas to the probed volume $(\alpha) 0.05$ is used to calculate the test spectrum. In Figure 1.A.1(a), the ontire test spectrum was fitted and the inferred temperature was found to be $1682.4 \mathrm{~K}$. The fit is not very good around the cold and hot bands. Fitting, performed by excluding 10 data points $(-1.9$ A) whose intensity is greater than half of the peak intensity, is shown in Figure 1.A.1 (b). The inferred temperature was $1987.4 \mathrm{~K}$, which is $305 \mathrm{~K}$ higher than the entire spectrum $f i t$. The wings of the cold and hot bands $f$ it better in this case because 1 ess weight is given to the data near the cold band peak and the inferred temperature is closer to the volume averaging temperature $(2115 \mathrm{~K})$ than fitting the entire spectrum.

Different data ranges, which were excluded from the $f$ it, were also examined to see the effect on the extracted temperature. The cholce of exclusion data range can affect the inferred temperature dramatically. The extracted temperature can be very close to the volume average temperature, if data corresponding to the spectral range Raman onift $2313.2-2331.1 \mathrm{~cm}^{-1}$ are excluded from the $\mathrm{fit}$. The hot and cold band tall can be fitted very well by excluding the above data range, as shown clearly in Figure 1.A.1(c).

A second data weighting method was also tested in which each data point was weighted inversely proportional to its intensity. Since relatively small weight is given to the data points around the cold band peak, the data around the hot band $f i t$ better. The inferred temperatures with this fitting method are generally closer to the volume averaging temperature. Figure 1.A.2 (a) shows a $f$ it with this weight ing method. The test spectrum used is the same as shown in Figure 1.A.1. The hot band can be fitted even better if the data points around the cold band peak are excluded from the fit. Figure 1.A.2(b) shows the fit excluding the data points between the Raman shift 2313.2 $2331.1 \mathrm{~cm}^{-1}$ with this weighting method. The extracted temperature from this fit was found to be $2121.6 \mathrm{~K}$, which is also very close to the volume averaging temperature.

The study of the error in the inferred temperature from bimodal spectra has also been performed for various values of $\alpha$. The results of this study are summarized in Table 1.A.1. It is clearly seen from this table that the temperature extracted from a bimodal spectrum is generally much colder than the volume averaging temperature. However, veasonable inferred temperature may be obtained by weighting data properly. No significant difference less than $30 \mathrm{~K}$ was found between the two weighting methods discussed above, if the data points between the Raman shift $2313.2-2331.1 \mathrm{~cm}^{-1}$ were excluded from the fit. This is because the high intensity cold band data were excluded Erom both methods, and the rest of the data have the same signal level. Therefore, equal weight for all fitted data points was applied to 

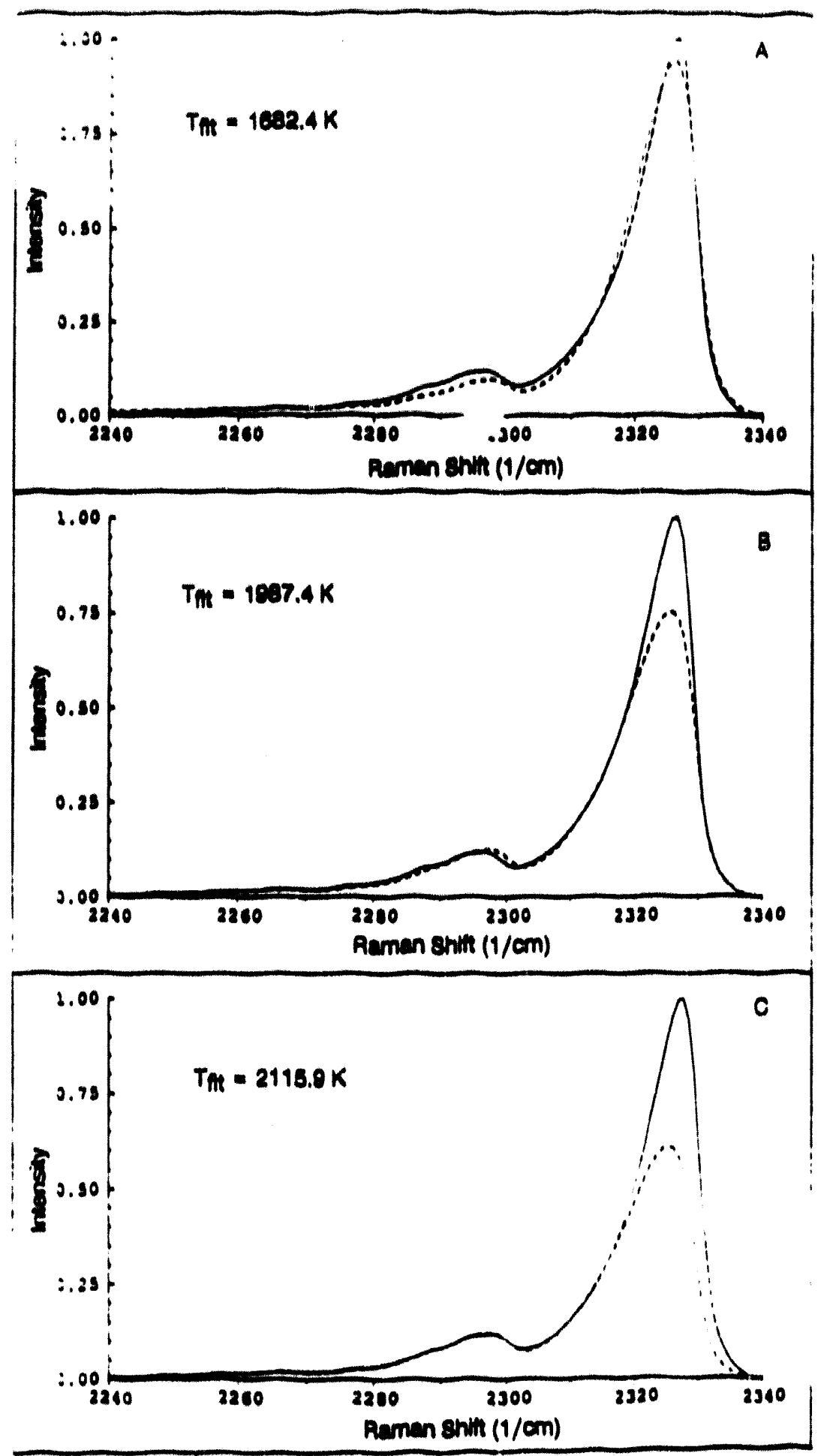

Figure 1.A.1

Fitting of a bimodal test spectrum with single temperature model. Each fitted data point was weighted equally.

(A) entire spectrum fit; (B) fit excluding 10 data points around the cold band peak; (C) fit excluding 21 data points which correspond to Raman shift 2313.2 to $2331.1 \mathrm{~cm}^{-1}$. 


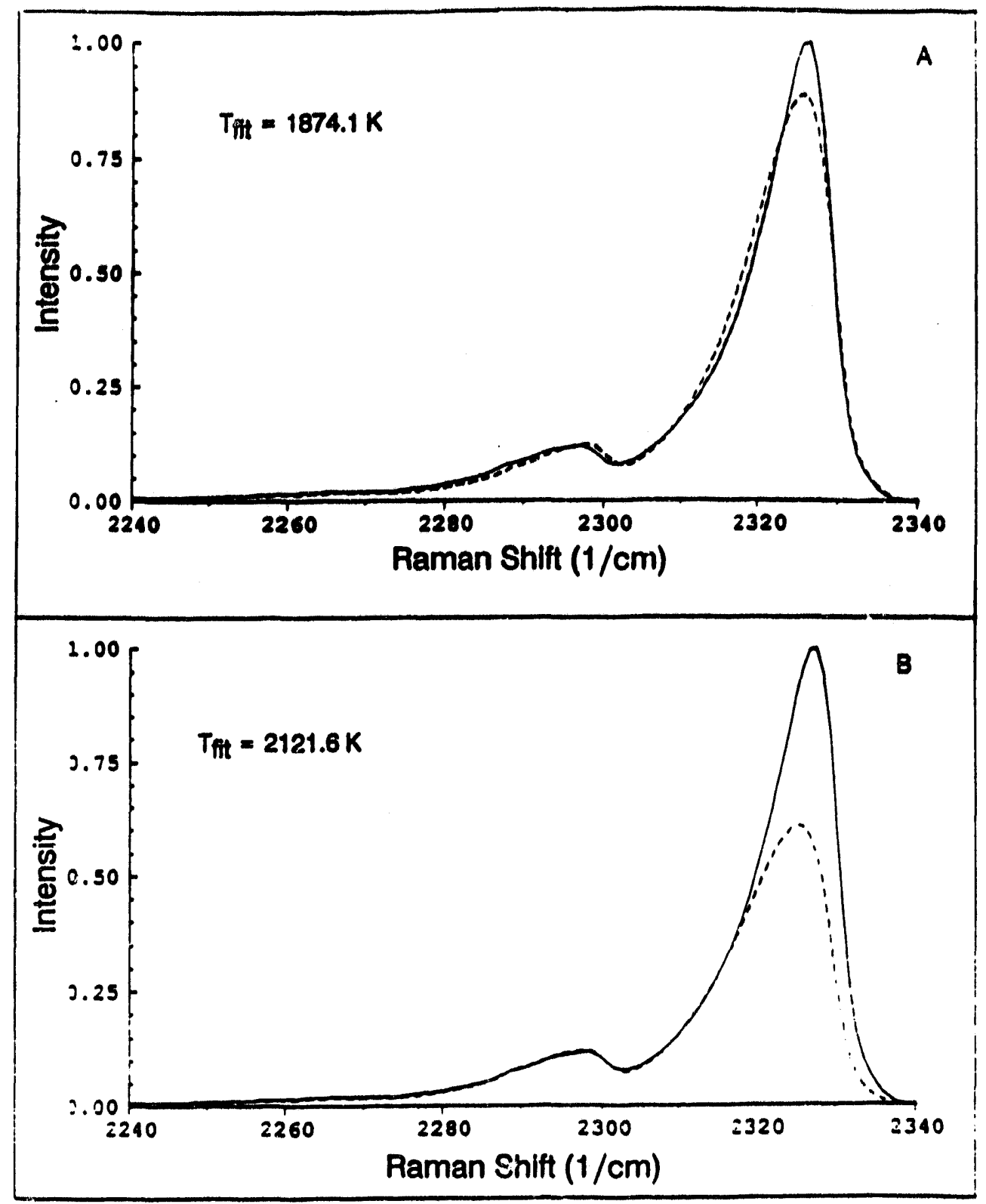

Figure 1.A.2

Fitting of a bimodal test spectrum with single temperature model. Each fitted data point was weighted inversely proportional to its intensity. (A) entire spectrum fit; (B) fit excluding 21 data points around the cold band peak. 
Table 1.A.1

Inferred temperature from a bimodal temperature spectrum. Stokes beam centered at $16420 \mathrm{~cm}^{-1}$; bandwidth $157 \mathrm{~cm}^{-1}$.

\begin{tabular}{|c|c|c|c|c|c|c|}
\hline \multirow{2}{*}{\multicolumn{2}{|c|}{$\begin{array}{c}\text { Test Spectrum } \\
T_{1}=500 \mathrm{~K}, T_{2}=2200 \mathrm{~K}\end{array}$}} & \multicolumn{5}{|c|}{ Inferred temperature (K) } \\
\hline & & \multicolumn{3}{|c|}{$W_{1}=1$} & \multicolumn{2}{|c|}{$W_{1}=\frac{1}{l_{1}}$} \\
\hline$\alpha$ & Tave (Volume) & $T_{\text {fit }}$ & $T_{\text {fit }}{ }^{a}$ & $T_{f i t}{ }^{b}$ & $T_{\text {fit }}$ & $T_{\text {fit }}{ }^{b}$ \\
\hline $\begin{array}{l}0.05 \\
0.10 \\
0.20 \\
0.40 \\
0.60 \\
0.80\end{array}$ & $\begin{array}{r}2115 \\
2030 \\
1860 \\
1520 \\
1180 \\
840\end{array}$ & $\begin{array}{r}1682.4 \\
1167.0 \\
786.3 \\
604.9 \\
544.6 \\
517.1\end{array}$ & $\begin{array}{r}1987.4 \\
1789.9 \\
1325.4 \\
761.0 \\
600.5 \\
537.2\end{array}$ & $\begin{array}{l}2115.9 \\
2034.0 \\
1857.3 \\
1479.1 \\
1332.7 \\
1230.0\end{array}$ & $\begin{array}{r}1874.1 \\
1603.7 \\
1080.1 \\
640.0 \\
582.2 \\
531.4\end{array}$ & $\begin{array}{l}2121.6 \\
2045.3 \\
1873.8 \\
1485.3 \\
1353.2 \\
1260.6\end{array}$ \\
\hline
\end{tabular}

a. 10 data points were excluded from the fit if $I_{\mathfrak{j}}>\frac{1}{2} I_{\text {peak }}$

b. 21 data points between the Raman Shift $2313.2-2331.1 \mathrm{~cm}^{-1}$ were excluded from the fit. 
all the analysis described below.

To further study the error of the temperature measurement with various beam waist and phase matching geometries, a theoretical CARS model was generated by integrating the signal along the overlap of the pump and stokes laser beams. The pump and stokes laser beams are assumed to satisfy the Gaussian intensity profile. To simplify the problem, the temperature and pressure are assumed to be uniform within the spot size of the laser beams. Therefore, the power of the antiStokes signal, generated at a distance $Z$ from the focal point, can be approximated $\mathrm{to}^{3}$

$$
P_{a s}(\mathrm{Z})=P_{a s}(0) \times\left(\frac{\omega_{p}(0)}{\omega_{p}(Z)}\right)^{4} \times\left(\frac{\omega_{g}(0)}{\omega_{g}(\mathrm{Z})}\right)^{2} \times\left(\frac{\omega_{a g}(\mathrm{Z})}{\omega_{a g}(0)}\right)^{2}
$$

where the $\omega(Z)$ 's are the spot size of the pump, stokes, and anti-stokes beams at a distance $Z$ from the focal point.

The CARS signal is generated along the overlapping of the pump and stokes laser beams. To calculate the simulated CARS spectrum, the electric field spectrum generated at different locations was calculated according to their power, temperature, and concentration, and then the individual spectrum was integrated for the final spectrum. The composite spectrum was compared with the theoretical spectrum calculated for single temperature, pressure and concentrations using a nonlinear least square algorithm." The error in the temperature due to spatial averaging can be expressed as the difference between the inferred temperature of the composite spectrum and the temperature at the focal point.

To study the quantitative contribution of CARS signals from various temperature regions, a simplified temperature profile for a gas stream was assumed and used for this analysis. The thermal model assumed is that of a symmetric flow $102 \mathrm{~mm}$ wide with a uniform hot gas flow of $2200 \mathrm{~K}$ and linear temperature fall off in the boundary region with a gradient of $148.8 \mathrm{~K} / \mathrm{mm}$. Away from the boundary, the temperature gradually falls to room temperature. "The effect of spatial averaging with various sizes of beam waists "was studied using the model described above. The CARS signals generated at various points were calculated for various beam waists and temperatures.

Figure 1.A.3(a) shows the calculated collinear CARS signal generated along the assumed gas stream with laser beam waists of 6.4 $\mu \mathrm{m}$ and the assumed temperature profile in that gas stream. The height of the dotted peak is the power of the CARS signal. The integration of these CARS signals generated across the gas stream produces the simulated CARS spectrum. It is obvious from the figure that the CARS signal is mainly produced around the focus point that is near the center of the gas stream in the case of the $6.4 \mu \mathrm{m}$ beam waist. A slight 


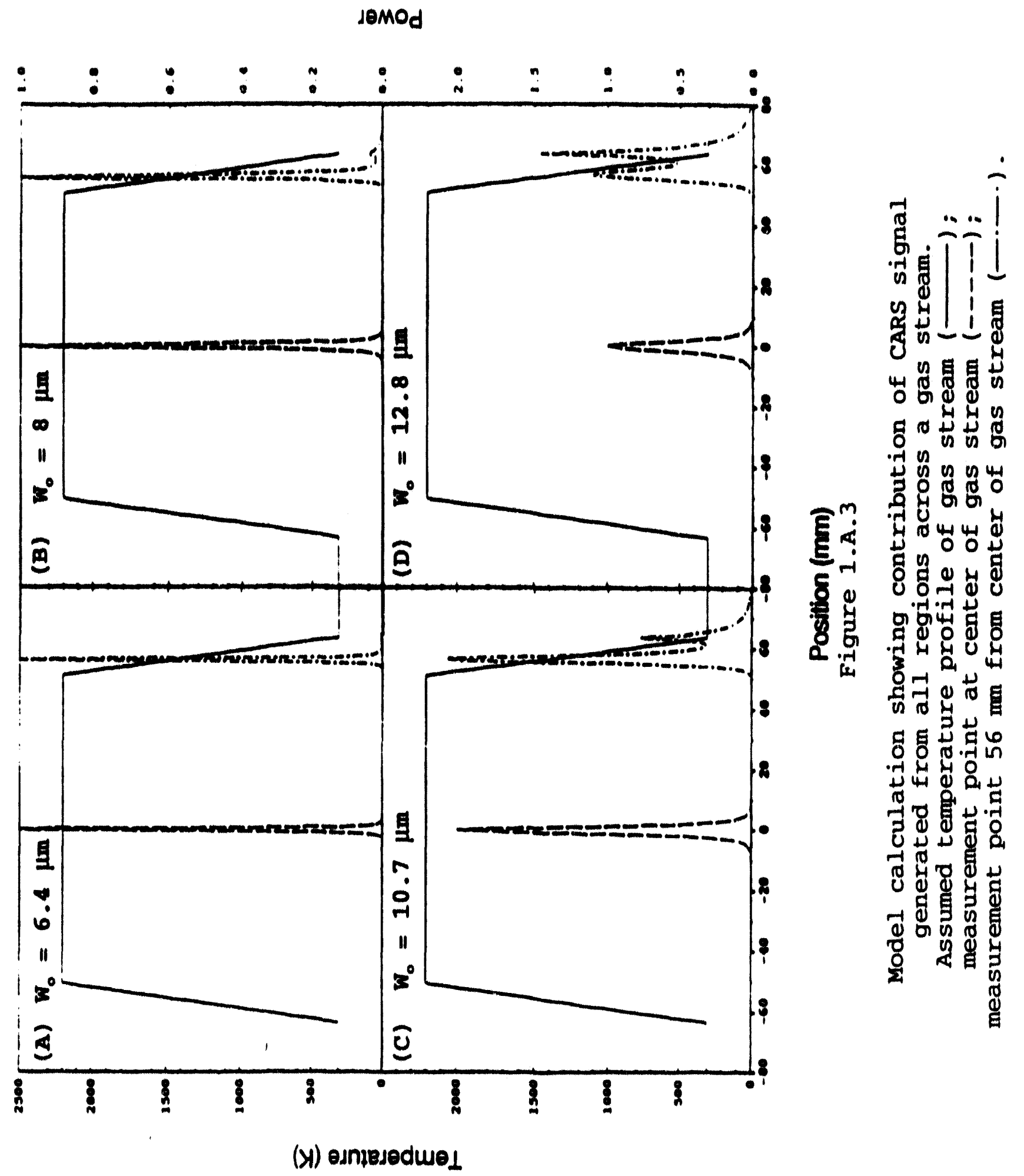

15601-44-JFM-91 
contribution from the cold region can be seen when the measurement point is moved to $56 \mathrm{~mm}$ from the center of the gas stream, which is the midpoint of the hot and cold region. The same type of calculations were performed for different beam waists and are shown in Figures 1.A.3 $(b-a)$.

The contribution from the cold region is negligible even with a bigger beam waist of $12.80 \mu \mathrm{m}$ when the focal point is at the center of the gas stream. Since the interaction length increases with the beam waist, the spatial averaging effect becomes more pronounced as beam waist increases. When the focal point is close to the gas stream boundary with a beam waist of $12.80 \mu \mathrm{m}$ the cold signal dominates. This is due to the higher gas density at a low temperature. Test spectra generated with three different beam waists $18,10.67$ and 12.8 $\mu \mathrm{m})$ at the center and $56 \mathrm{~mm}$ away from the center of the gas stream were analyzed by fitting the composed spectrum with computer-simulated spectra. The inferred temperatures were obtained by fitting the entire spectrum. The analysis was also performe d by excluding 21 data points around the cold band peak. These analysis results are summarized in Table 1.A.2. The inferred temperatures from the data generated at $38.1 \mathrm{~mm}$ away from the center of the gas stream are the same, or almost the same, as the true temperature for the three different spot sizes. The inferred temperature for the data at $57.15 \mathrm{~mm}$ from the center of the gas stream is 75 to $450 \mathrm{~K}$ lower than the true temperature depending on the beam waists. The error is lower with a $8 \mu \mathrm{m}$ beam waist than with a $12.8 \mu \mathrm{m}$ beam waist due to shorter interaction length (less cold contribution) with the $8 \mu \mathrm{m}$ beam waist. Inferred temperature can be very close to the true temperature if 21 data points $(-4$ A) around the cold band peak corresponding to the Raman shift 2313.2 to $2331.1 \mathrm{~cm}^{-1}$ are excluded from the fit.

The temperature profile, extracted from the simulated collinear CARS data, was also examined by fitting the composed spectra across the length of the gas stream. The test spectra were generated with the beam waist of $12.8 \mu \mathrm{m}$. The data were generated by two methods. First, the $\mathrm{N}_{2}$ spectrum is generated assuming an $\mathrm{N}_{2}$ mole fraction of 0.6 in all temperature regions. This will be the case where no attempt has been made to reduce the unwanted signal generated between two focal lenses. Second, the CARS signal is generated with an $\mathrm{N}_{2}$ mole fraction of 0.6 at the hot gas stream $(T>500 \mathrm{~K}$ ) and 0.05 elsewhere. The entire test spectrum was fitted with the model with the equal weighting method. The extracted temperature profiles from these two sets of data are shown in Figure 1.A.4 along with the assumed temperature profile. Temperature is the major fitting parameter in the analysis. It is clearly seen from Figure 1.A.4 that both the profiles are distorted. The distortion is more serious when the $\mathrm{N}_{2}$ mole fraction of 0.6 is assumed in all regions. The temperature profile obtained from the data with an $\mathrm{N}_{2}$ mole fraction of 0.05 outside the gas stream is closer to the true profile. The inferred temperatures are always lower than the true value when the measurement point is $63 \mathrm{~mm}$ away from the center of the gas stream. 
Table $1 . \mathrm{A} .2$

Effect of beam waist and temperature gradient at probed volume to the error introduced into the temperature measurement.

Test spectrum generated by integrating CARS signal generated along overlap of pump and stokes beams.

\begin{tabular}{|c|c|c|c|c|}
\hline $\begin{array}{c}\text { Bean watst } \\
\text { Wo }(\mu \mathrm{m})\end{array}$ & $\begin{array}{c}\text { Position } \\
(\mathrm{mm})\end{array}$ & $\begin{array}{c}T \\
(\mathrm{~K})\end{array}$ & $T_{\text {fit }}(\mathrm{K})$ & $T_{\text {fit }}$ (K) a \\
\hline 8.00 & 38.10 & 2200.0 & 2198.9 & 2199.8 \\
& 57.15 & 1255.0 & 1180.6 & 1237.4 \\
\hline 10.67 & 38.10 & 2200.0 & 2188.9 & 2198.3 \\
& 57.15 & 1255.0 & 1009.0 & 1214.2 \\
\hline 12.80 & 38.10 & 2200.0 & 2162.2 & 2195.0 \\
& 57.15 & 1255.0 & 805.4 & 1178.4 \\
\hline
\end{tabular}

a) excluding 21 data points around the cold band peak. 


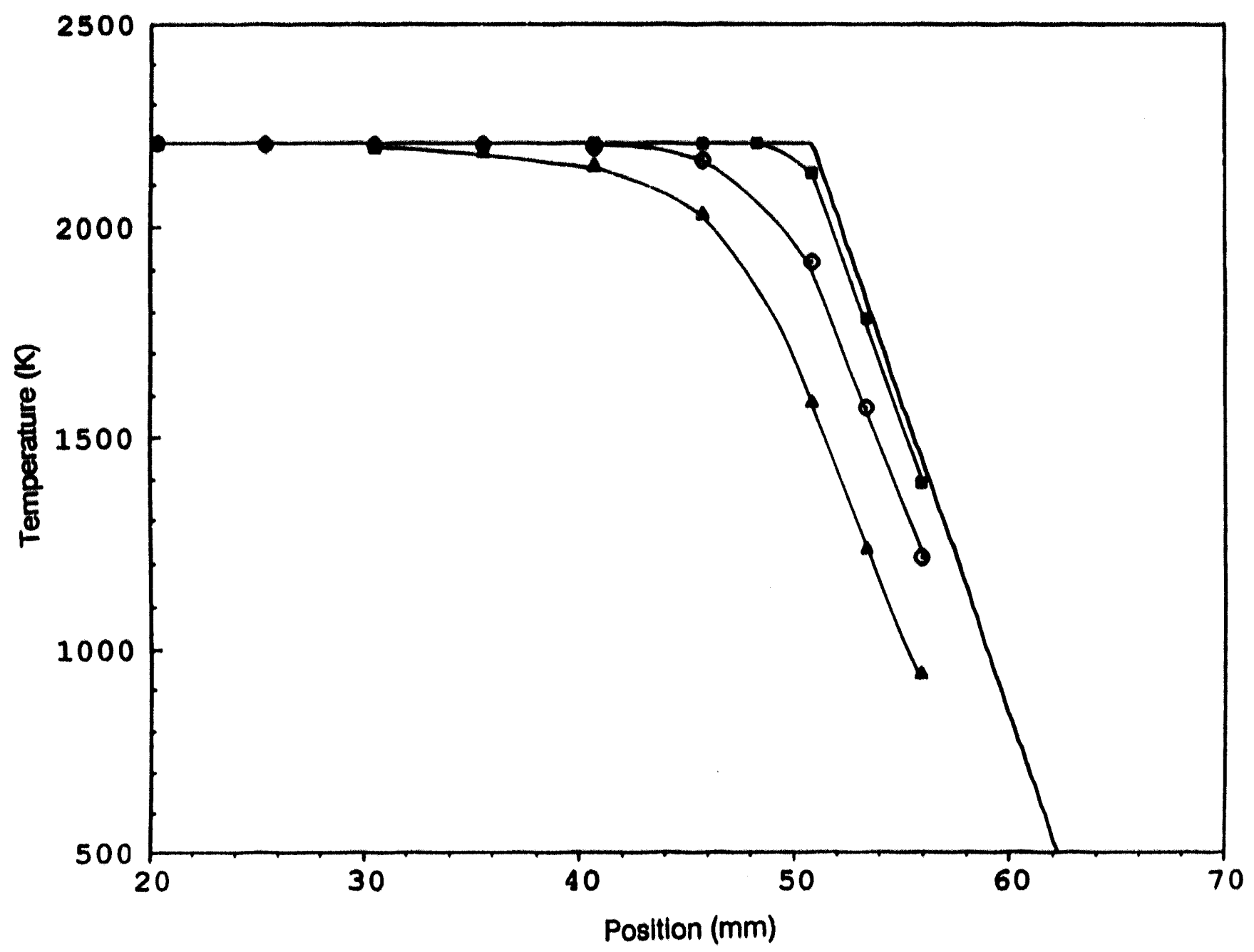

Figure 1.A.4

Temperature profiles: (-) assumed temperature profile;

(0) extracted from simulated collinear CARS data, $f_{\mathrm{N} 2}=0.6$ for $\mathrm{T}>500 \mathrm{~K}, \mathrm{f}_{\mathrm{N} 2}=0.05$ elsewhere;

(A) extracted from simulated collinear CARS data,

$f_{\mathrm{N} 2}=0.6$ in all regions; (D) extracted from simulated BOXCARS data, $\mathrm{f}_{\mathrm{N} 2}=0.6$ in all regions. 
The same type of study with BOXCARS geometry was also performed. The $\mathrm{N}_{2}$ mole fraction of 0.6 is assumed for all regions. The beam waist was again assumed to be $12.8 \mu \mathrm{m}$. The simulated spectrum was calculated by integrating the electric field spectrum generated within the interaction volume. The interaction length is assumed to be $1.5 \mathrm{times}$ that of the confocal parameter. The result of this study is also shown in Figure 1.A.4. The calculated temporature profile for BOXCARS geometry is closer to the assumed temperature profile than that of collinear CARS. However, a 50 to $100 \mathrm{~K}$ lower inferred temperature was also found for the measurement made close to the boundary.

To compare the results of the theoretical analysis described above with the experimental study, CARS temperature profile measurements were made with both collinear and folded BOXCARS techniques in a laboratory burner and DIAL's test stand with the mobile CARS instrument. The temperature profile measurements in a laboratory burner with the collinear CARS geometry was performed and reported earlier. ${ }^{5}$ The burner produces an $=11-\mathrm{cm}$ long, $1.5-\mathrm{cm}$ wide $f$ lame. The ratio of the flow rate of the $\mathrm{CH}_{4}$ and air was adjusted to achieve a stable flame. Argon purge was used at both ends. The temperature measurements with folded BOXCARS were made with the same running conditions as the collinear CARS burner measurements. A $30-\mathrm{cm}$ focal length lens was used to focus the laser beam $10 \mathrm{~mm}$ above the surface of the burner. The extracted temperature profile of a $\mathrm{CH}_{4} / \mathrm{air}$ flame from the folded BOXCARS measurements is shown in Figure 1.A.5. The average temperature across the flame was found to be $2200 \mathrm{~K}$, and it is in agreement with the measurements obtained from the collinear CARS measurements. The temperature at the center is $2100 \mathrm{~K}$ and increases linearly to $2250 \mathrm{~K}$ on both ends of the flame. The dip at the center of the temperature profile was not observed in the collinear CARS measurements. A series of temperature profile measurements was made with folded BOXCARS to check the reproducibility of the dip. The dip is present in all the profile measurements with the $30-\mathrm{cm}$ focal length lens. To study the effect of beam waist or interaction length on the dip, CARS data were taken with a $100-\mathrm{cm}$ focusing lens. A dip also exists in the temperature profile extracted from the $100-\mathrm{cm}$ focal length lens measurements, but it is less pronounced than that from the $30-\mathrm{cm}$ focal length lens measurements due to longer interaction length. The temperature gradient at both boundaries of the extracted temperature profile is slightly lower in the folded BOXCARS measurements than that from collinear CARS. The sharper temperature gradient in the collinear CARS measurements might be due to the shorter flame length caused by the argon purge from the argon cells on both ends of the burner.

To test the temperature measurements in a larger gas stream, $\mathrm{N}_{2}$ CARS measurements were made in DIAL's test stand at a port $87 \mathrm{~cm}$ downstream from the combustor. Coal, fly ash and potassium seed $\left(\mathrm{K}_{2} \mathrm{SO}_{1}\right)$ were injected into the combustor to simulate an MHD gas flow during the measurements. The mobile CARS lasers were aligned with the test stand, which was at a distance of $-20 \mathrm{~m}$ from the mobile laboratory. Temperature profile measurements were made with both folded BOXCARS 


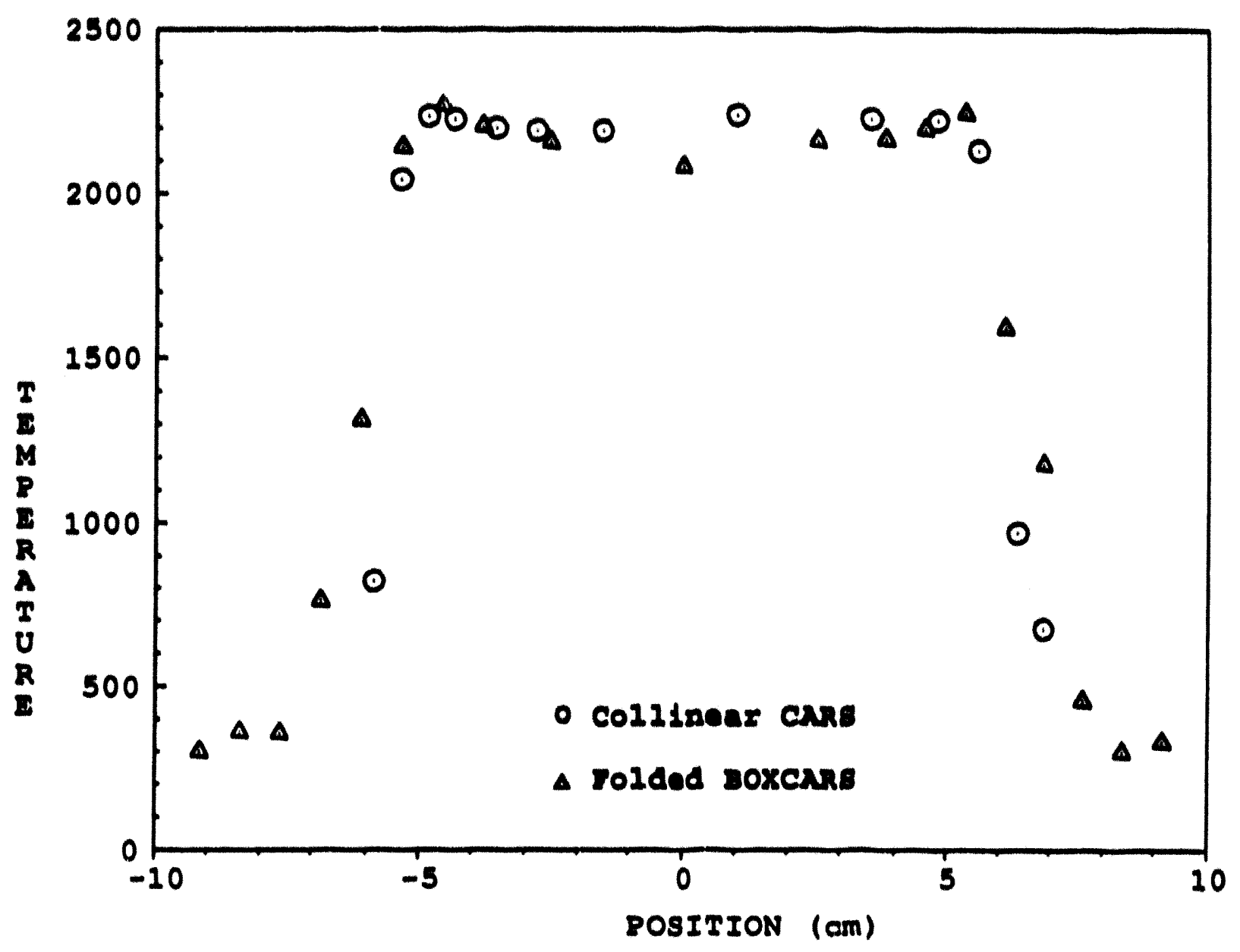

Figure 1.A.5

Temperature profile of flat flame burner $10 \mathrm{~mm}$ from the burner surface with folded BOXCARS, collinear CARS, and $30-\mathrm{cm}$ focal length lens. 
and collinear CARs techniques.

The measurement were first made with the collinear CARS geometry. The optics ports of tho DIAL test stand are usually purged with dry nitrogen to cool and reduce deposits on the windows; however, in the case of the collinear CARS measurements, the ports have to be purged with argon to eliminate the cold $\mathrm{N}_{2}$ contribution due to the $\mathrm{N}_{2}$ purge. Since a long focal length lens is needed for measuring the large gas stream in DIAL's test stand, the laser beams were expanded to -50 mon in diameter at the fleld lens to produce amaller beam walst with collinear CARS. A GG-495 filter was mounted on the entrance port window and $532-\mathrm{nm}$ dichroic mirror attached to an argon-purged $\mathrm{Al}$ cell was placed on the exit port window to liminate the CARS signal generated outside the gas stream. The $\mathrm{N}_{2}$ CARS spectra recorded at the center of the $20.5-\mathrm{cm}$ gas stream with argon and $N_{2}$ purge active are shown in Figure 1.A.6. The stoichiometry of the run was $\phi=1.05$. The spectrum, recorded with $\mathrm{N}_{2}$ purge at the port windows, was dominated by the cold CARs ignal generated between the port windows and the gas stream, as shown in Figure 1.A.6. The argon purge can effectively eliminate the CARS contribution from the cold region. Therefore, the spectrum with argon purge looks much hotter than that with $\mathrm{N}_{2}$ purge. It can be easily identified by comparing the $\mathrm{N}_{2}$ CARS hot bands IV - $1 \rightarrow 2$ and $2 \rightarrow 3$ ). Fitting of the spectrum taken with the argon purge active shows that a sight CARs signal was still generated from the cold region.

To study the feasibility of making temperature profile measurements in a practical combustor with collinear CARs, measurements were made in DIAL's test stand with the argon purge. The extracted profile is shown in Figure 1.A.7. The focal length of the focusing lens was $100 \mathrm{~cm}$ and the diameter of the laser beam was $50 \mathrm{~mm}$ at the focusing lens. The extracted temperature, $2470 \mathrm{~K}$, is fairly uniform across the gas stream (within $7.6 \mathrm{~cm}$ ). It starts decreasing at 7.6 to $10 \mathrm{~cm}$ from the center of the gas stream. The temperature inside the port $(10 \mathrm{~cm}$ away frum the center of the gas stream) decreases very slowly. To compare the collinear CARs temperature profile measurements with argon and $\mathrm{N}_{2}$ purge, CARS data were also taken across the gas , tream with $\mathrm{N}_{2}$ purge. The temperature profile measurements with argon and $N_{2}$ purge have similar shapes, but the overall lower temperature found in the $\mathrm{N}_{2}$ purge measurements shows the data obtained with $\mathrm{N}_{2}$ purge cannot be used to accurately measure the temperature. If data taken with $\mathrm{N}_{2}$ purge were fitted by excluding the data points in the spectral range $\left(2310-2332 \mathrm{~cm}^{-1}\right)$, the extracted temperature near the center of the gas stream can be very close to that extracted from argon purge data. However, the inferred cemperature from the data taken near the boundary is not effectively changed with this fitting method.

Temperature profile measurements were also performed with folded BOXCARS with a $60-\mathrm{cm}$ focal length focusing lens. The temperature profile obtained is shown in Figure 1.A.8. The inferred temperature of the argon purge data taken from the position -7.6 to $7.6 \mathrm{~cm}$ away 


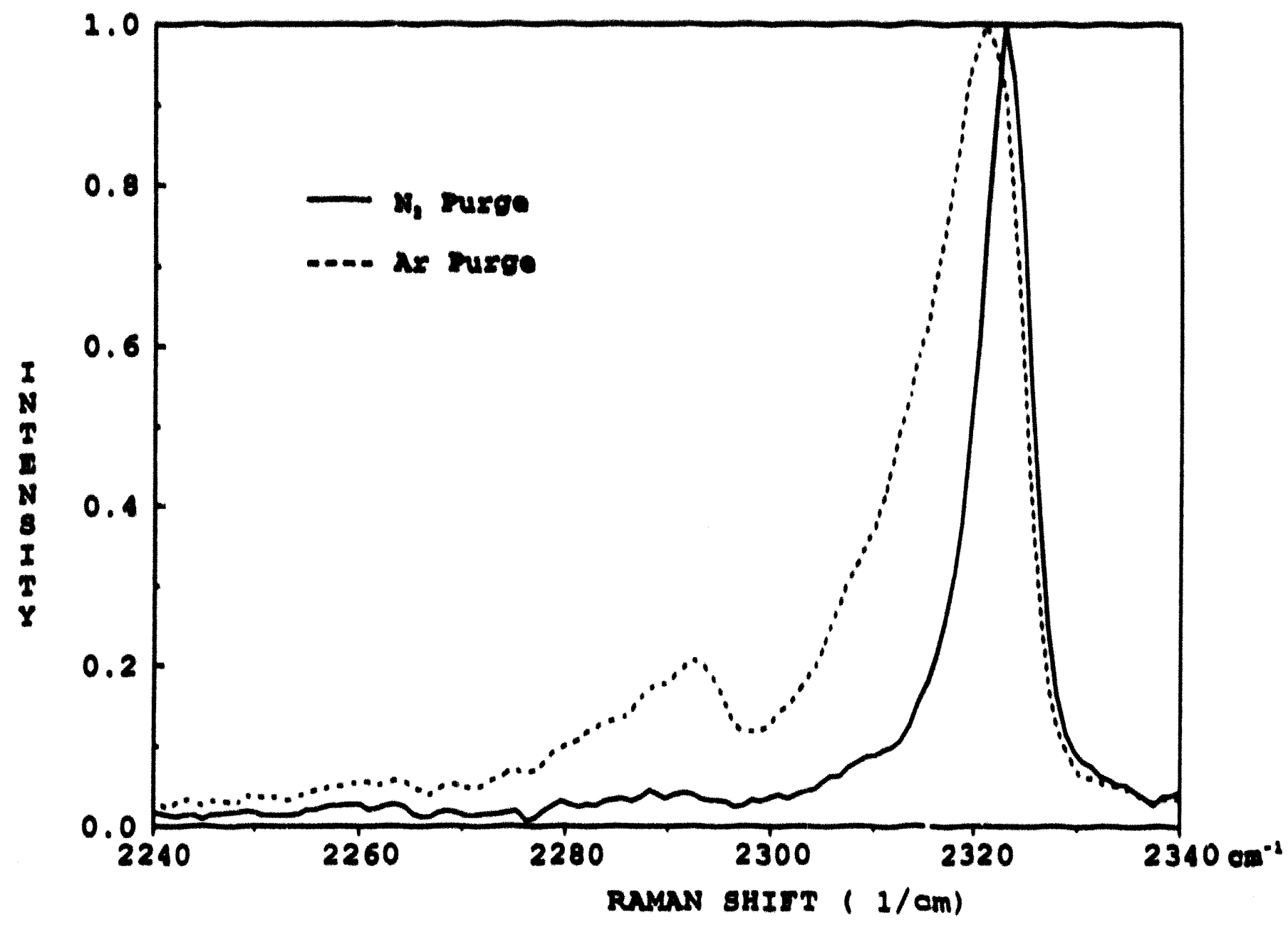

Figure $1 . A .6$

$\mathrm{N}_{2}$ CARS spectra recorded at center of DIAL test stand with colIinear CARS and $\mathrm{N}_{2}$ and argon purge (lens focal length $-100 \mathrm{~cm}$ ). 


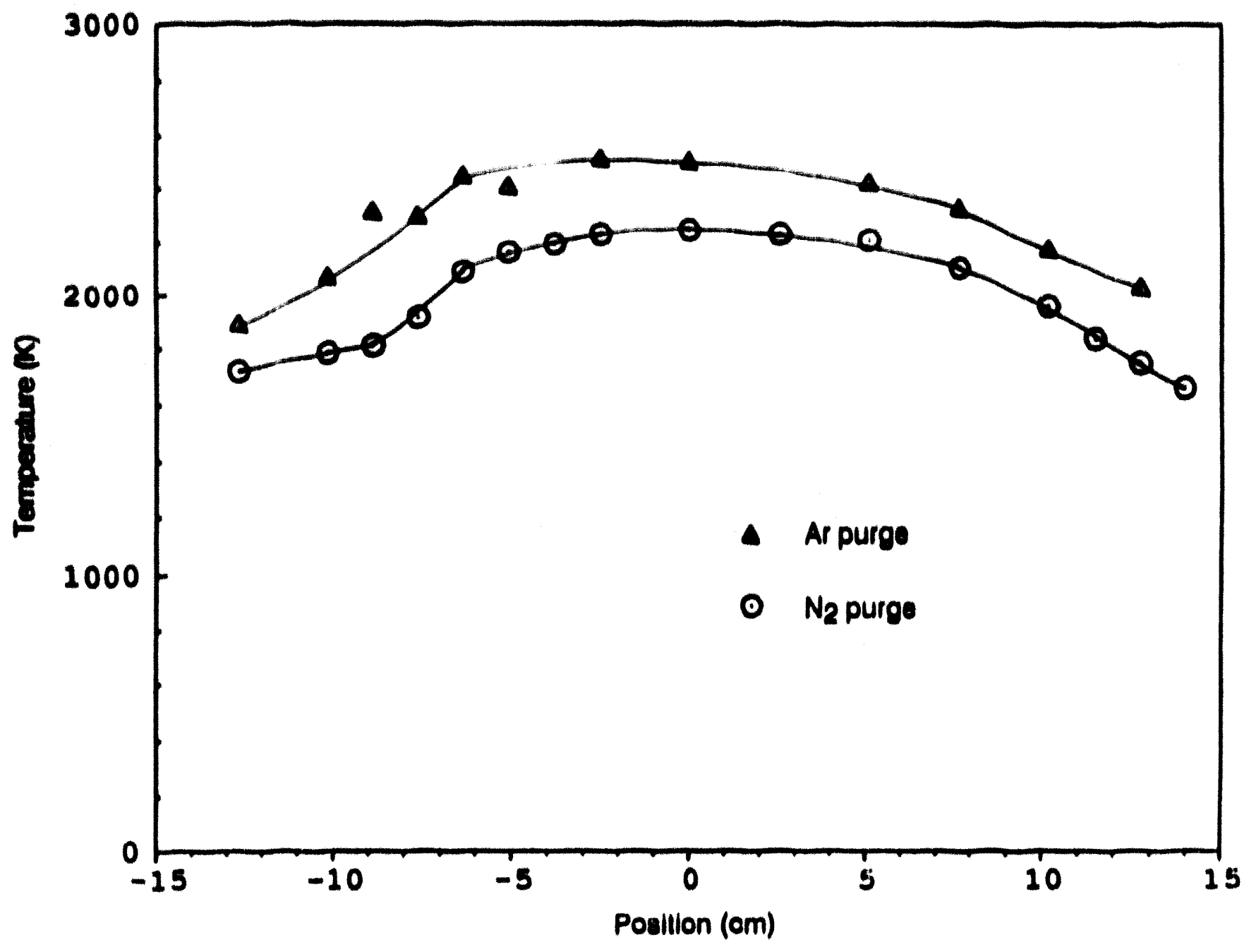

Figure 1.A.7

Temperature profile measured with folded BOXCARs across

DIAL test stand at a port $87 \mathrm{~cm}$ downstream from the combustor with $\mathrm{N}_{2}$ and argon purge (stoichiometry - 1.05 ). 


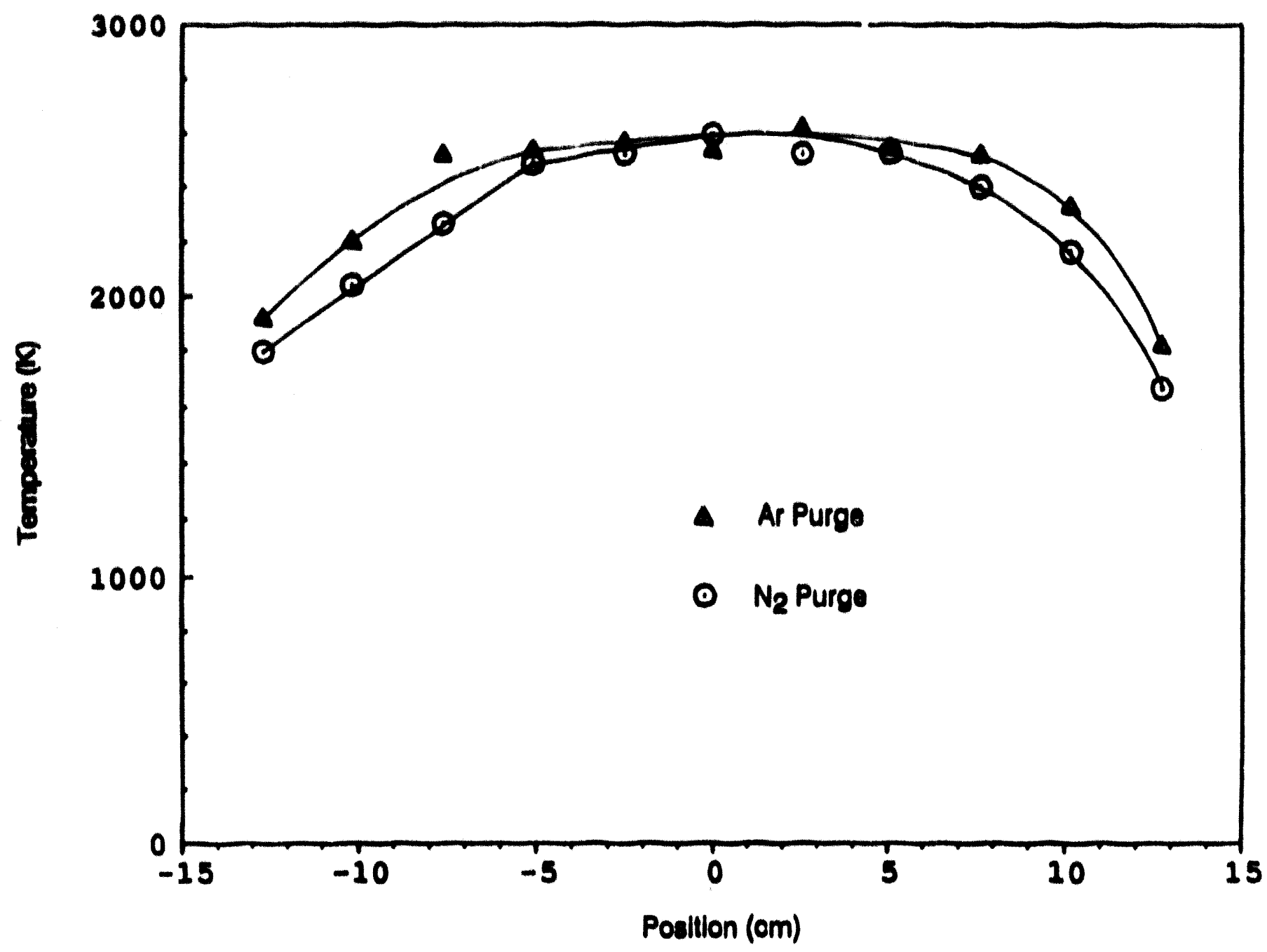

Figure 1.A.8

Temperature profile across DIAL test stand measured with collinear CARS at a port $87 \mathrm{~cm}$ downstream with $\mathrm{N}_{2}$ and argon purge (lens focal length - $100 \mathrm{~cm}$, stoichiometry - 1.05). 
from the center of the gas stream is almost constant and found to be $2540 \mathrm{~K}$. To study the effect of the cold CARS contribution on temperature profile measurements, spectra were also recorded with $\mathrm{N}_{2}$ purge. The results of these measurements are also shown in Figure 1. A.8 for comparison. Temperature from -5 to $5 \mathrm{~cm}$ agreed with the measurement with argon purge. A lower temperature was found close to the boundary of the gas stream and inside the optical port as clearly seen in the figure.

Temperature profile measurements with folded BOXCARS (Figure 1.A.8) and collinear (Figure 1.A.7) CARS are compared to evaluate the collinear CARS temperature meas rements. The comparison is mainly for the argon purge data since the $\mathrm{N}_{2}$ purge data has been known to have more problems. Although the combination of a $100-\mathrm{cm}$ focusing lens and $50-\mathrm{mm}$ diameter laser beams used in the collinear CARS measurements produced a beam waist smaller than the one produced with a combination of a $60-\mathrm{cm}$ lens and $15 \mathrm{-mm}$ diameter laser beams in the folded BOXCARS measurements, a poorer spatial resolution was still found in the collinear CARS measurements. The shape of these two profiles are very similar, but the tomperature obtained across the gas stream in the collinear CARS measurements is $-40 \mathrm{~K}$ lower than that with the folded BOXCARS measurements. The temperature profile close to the boundary is sharper in the folded BOXCARS measurements than in the collinear CARS measurements.

Work on the CARS measurement of the $C O$ concentration in a particle-laden environment has been delayed because of problems with the Nd:YAG laser. The $Q$ switch was sent to Cleveland Crystal for repair. A laser service representative from Spectra Physics installed the repaired $Q$ switch in the DCR-4 laser and realigned the laser system. A reasonably high laser power can now be achieved.

\section{Conclustone}

The theoretical and experimental studies for both sollinear and folded BOXCARS phasematching geometries were performed. Studies show that BOXCARS is the best choice for measurement in a practical environment. But the CARS data taken near a high temperature gradient area or in a turbulent flame may produce a multimodal spectrum. Care is still needed to analyze that type of data. In a turbulent environment it is better to record single shot CARS data to establish the temperature histogram for more reliable temperature information.

\section{Work Forecast}

Work will continue to measure the co concentration in a particleladen combustion environment. The comparative study of the various phase matching geometries to evaluate these techniques for field application will also continue. The origin of the atypical feature observed in the $\mathrm{N}_{2}$ CARS spectrum at the CFFF will continue to be investigated. 


\section{References}

1. Boquilion, J.P.; Pealat, M.; Bouchardy, P.; Collin, G.; Magre, P.; and Taran, J.P. 1988. Spatial averaging and multiplex coherent anti-Stokes Raman scattering temperature measurement error. Opt. Lett. $13: 722-724$.

2. Shepherd, I.G.; Porter, F.M.; and Greenhalgh, D.A. 1990. Spatial resolution effects of CARS in turbulent premixed combustion thermometry. Combust. Flame. 82:106-109.

3. Singh, J.P. and Yueh, F.Y. Comparative study of the temperature measurement with folded BOXCARS and collinear CARS. Combust. Flame. Submitted 1991.

4. Yueh, F.Y. and Beiting, E.J. 1988. Simultaneous $\mathrm{N}_{2}$, CO and $\mathrm{H}_{2}$ multiplex CARS measurements in combustion environments using a single dye laser. Appl. Opt. 27:3233-3243.

5. Singh, J.P. and Yueh, F.Y. 1990. DIAL Quarterly Technical Progress Report. FE-15601-40:32-41. 


\section{$1 . B$ Particle size Distribution Syotem (PSD)}

W. Okhuysen, Principal Investigator

\section{Work Performed}

While mindful of the mission of this task, there is nothing to report for this quarter. 


\section{C Potageium Imiseion/Abrorption syetem (PI/AS)}

L. E. Bauman, Principal Investigator

Work Performed

While mindful of the mission of this task, there is nothing to report for this quarter. 


\section{D Intrue1ve Mult1-Probe syetem (INPS)}

$L$. R. Hester and $C$. $W$. Bouchillon, Principal Investigators

\section{Work Performed}

The intrusive lightpipe sensor has been repaired and a spare is being fabricated. A change in operational procedures has been made to minimize damage to the probe during normal operations. An 80386based computer has been obtained for dedicated use for the control of the IMPS and for simultaneous data acquisition from the probe. Software development has been delayed because of the late delivery of the hardware.

Some progress was made on the development of the software; however, some work remains to be done. plans were made to calibrate the new sensors for use during the CFFF LMF4-W experiments in May. The optics were received for use with the SLR probe system. Preliminary efforts to incorporate these optics into the IMPS have been made.

\section{Work Forecast}

Completion of the new hardware integration into the IMPS, with further software development for appropriate implementation, will be undertaken. Calibration of the lightpipe sensor system will be accomplished using a blackbody source temperature device. The lightpipe sensor will then be used for surface temperature measurements of the test regions of the soot blowers at the CFFF in May. Further efforts will be expended toward completion of the SLR probe system during the next period. 


\section{Faraday Rotation Byotem (NRS) \\ L. E. Bauman, Principal Investigator}

\section{Work Parformed}

While mindful of the mission of this task, there is nothing to report for this quarter. 


\section{F Mult1-Purpose Imaging Syetem (MPIS)}

R. K. Lengel and J. S. Lindner, Principal Investigators

\section{Work Performed}

Further experiments on the potassium LIF (4S - 5P transition) were initiated. Results indicated that the transition could be saturated; however, some degradation of beam quality was observed resulting in a nonuniform intensity across the expanded beam. Ef forts to improve beam quality were undertaken by repairing the Nd: YAG laser. These were partially successful and further improvements in beam quality are in progress. Problems with the CID camera and the computer were repaired.

\section{Work Eorecant}

New parts for the laser have been ordered. These will be installed when received and the laser will be completely realigned. This should solve the nonuniformity problems. 


\subsection{Differential Absorption Laser Spectroscopy Syotem (DALAS)}

D. L. Monts, Principal Investigator

\section{Work Performed}

Work has progressed satisfactorily on the DALAS system for measurement of line-of-sight average species concentration. The true bandwidth of the two-color dye laser oscillator, operating at a single wavelength, has been verified to be $0.005 \mathrm{~nm}$ FWHM in the rhodamine 6G dye lasing region, by using a Fabry-Perot etalon. A collimating telescope has been placed between the output of the dye laser oscillator section and the amplifier dye cell. This reduced the dye laser beam diameter to approximately $2 \mathrm{~mm}$ and also reduced the fullangle beam divergence to $1.4 \mathrm{mrad}$. A beam splitter is used to direct 108 of the initial $532-\mathrm{nm}$ Nd:YAG beam onto the oscillator dye cell and the remaining 90\%, after being optically-delayed, is directed onto the amplifier dye cell. At $565 \mathrm{~nm}$ with $170 \mathrm{~mW}$ of initial $532-\mathrm{nm}$ Nd:YAG laser power, the output of the dye laser is $17.8 \mathrm{~mW}$; this corresponds to $10 \%$ conversion efficiency, which is typical for dye lasers. Thus, the construction, testing and optimization of the dye laser operation at a single wavelength has been completed.

An optical cell/vacuum system for bench-top studies of $\mathrm{NO}, \mathrm{SO}_{2}$, and other species of interest has been designed, and the components have been ordered. This system will allow monitoring of the DALAS signals of known concentrations of NO (or other species) at room temperature, enabling development of the methodology required for accurate species concentration measurements. When this has been accomplished, DALAS will be used to measure the concentration of NO first in a bench-top flame and then in the DIAL test stand before being field tested.

Design of the photodetector circuit has begun. In addition to detecting the transmitted laser intensity, the photodetector circuit will also switch the signal output between two boxcar averager modules so the transmitted intensities of the resonance and off-resonance wavelengths can be independently determined. These two intensities (plus the intensities of the two wavelengths just before the sample) are required for determination of species concentration.

A computer program for rotating the dye laser's beam-steering glass plate for production of alternating wavelengths (see Figure 1.G.1) has been completed and testing of the program has begun. When testing is complete, then the two-color mode of dye laser operation will be characterized and optimized.

Progress was slowed by the problem with Nd:YAG laser. This laser is shared by the DALAS, LOGS, and CARS systems. In February, it was discovered that the $Q$ switch installed last year had been severely damaged and had to be rebuilt. It was also discovered that the Nd:YAG laser beam diameter shrank by almost half when the laser amplifier was turned on, and it shrank still more when the laser was run for 


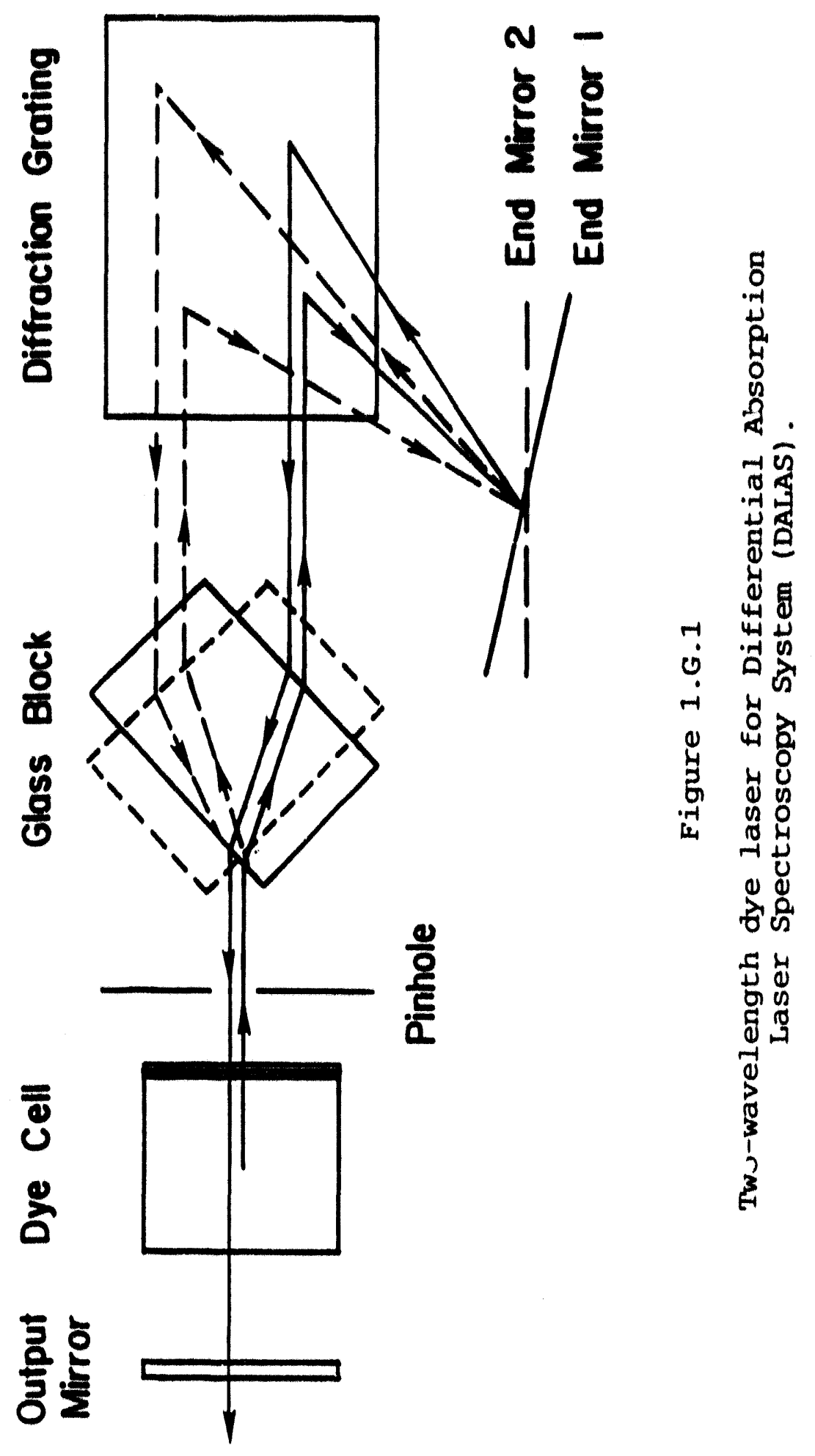


30 minutes. The small laser beam diameter was capable of severely damaging optics many meters away from the laser. A service representative installed the rebuilt $Q$ switch and eliminated the laser beam focusing problem.

\section{Conoluston:}

Progress on the DALAS project has been satisfactory, but the need for frequent laser repair threatens progress of any DALAS ef forts that require the Nd:YAG laser.

\section{Work rorecant}

After the end of the quarter, the Nd:YAG laser's recently repaired $Q$ switch was again found to be severely damaged and in need of rebuilding. Consultation with the manufacturer has revealed that several research groups across the country are having analogous problems. It is believed that the $Q$ switch manufacturer has changed the materials and/or manufacturing processes. Until the manufacturer resolves this problem, we do not anticipate long periods of troublefree operation for the Nd:YAG laser. Therefore, although efforts to achieve, characterize, and optimize two-color dye laser operation will be made during the next quarter, progress may be limited to efforts which do not require the laser. These efforts will include construction and testing of the optical cell/vacuum system for benchtop studies, design and construction of the photodiode/switching circuit, and selection of laser resonance and of $f$-resonance wavelengths for studies of NO, etc. 


\section{H Lacer Optogalvando speotroscopy syetem (LOOS)}

D. L. Monts, Principal Investigator

\section{Work Partormed}

Work has progressed slowly, but satisfactorily, on the LOGS system for determination of system temperature, and for quantitative identification of atomic and molecular species. Investigation in a clean bench-top flame of the effects of electrode aging and of the build up (fouling) on the electrode of an oxide coating on the LOGS signal intensity has been completed. The results qualitatively show that the efects of aging and fouling are related to the flame temperature, the fuel/oxidant ratio, and to the position of the lect rode in the bench-top $t$ lame. Changes in the LOGS signal intensity of an atomic potassium transition were monitored, for up to 14 hours, as a function of burning time. When the lectrode was in the interconal zone of a fuel-rich methane/air tlame, the oxide coating was observed to build up and suddenly fall off, producing a large, transient increase in the LOGS signal intensity. The period required for build up and fall of $f$ of the oxide coating decreases with increasing burning time. The electrode diameter is measured to decrease with increasing burning time. When the electrode is in the outer diffusion zone of the bench-top methane/air flame, the oxide coating builds up, but remains on the electrode. The electrode diameter increases with increasing burning time.

Design of an apparatus to permit observation of atomic LoGs signals on the DIAL test stand has begun. Observation of the LOGS spectrum of an atomic species in the DIAL test stand will permit the use of an intense, well-characterized LOGS signal to develop the apparatus essential for application of LOGS to practical combustion systems in the field. Progress was slowed by the problems with the Na:YAG laser which were discussed in section 1.6 of this report.

\section{Conclustons}

Pjogress on the LOGS project has been satisfactory, but the need for frequent laser repair threatens to slow future progress.

\section{Work Forecast}

As discussed in section 1.G, we are not optimistic that the Nd:YAG laser will be operational for long, trouble-free periods of operation. Assuming the laser remains operational, efforts for developing LOGS as a monitor of gas temperature will be two pronged. First, observation of LOGS signals of atomic species will be made in the DIAL test stand. Second, observation of LOGS signals of molecular species will be made in bench-top flames. Determination of temperature is far more accurate when molecular rather that atomic species are utilized, thus, ef forts to observe the LOGS spectrum of molecular species is essential for these efforts. Observation of the LOGS spectrum of an atomic species in the DIAL test stand will permit the use of intense, well-character- 
Ized LOGS ignals to develop the apparatus esential for application of LOGS to practical combustion syatems. Because of the expense of operating the DIAL test stand, these efforts will also involve sudies of lectrode behavior utilizing the method of Beiting and singh to inject fly ash into a bench-top flame.'

\section{Rotezenoes}

1. Beiting, E.J. and Singh, J.P. 1986. Simple particle infection system for laboratory burners. Rev. Sci. Inst rum. 57:377-379. 


\section{$1 . I$ Crose Corredation syotem (CCS) \\ O. P. Norton, Principal Investigator}

\section{Work Partormod}

A paper, based on cross correlation measurements on the DIAL combustion test stand, was presented at the AIAA 29th Aerospace Sciences meeting held in Reno, Nevada, January $7-10,1991 .{ }^{\prime}$ Analysis of data from the DIAL test stand, as well as the data obtained during the CFFF LMF4-V test in November 1990, continues.

Hardware and software necessary for this project continues. An array processor to speed up the real-time computation of cross correlation functions from the data has been received. The Microsoft Windows Software Development Kit has been acquired for use in writing software for the syotem. Currently, we are in the initial stages of software writing to take data and compute the cross correlation in real time, as opposed to storing data to a disk and analyzing it later on the VAX.

\section{Work Poreount}

The remaining items in this year's budget will be acquired during the next quarter. Effort on this system for the next few months will be devoted to the development of software.

\section{Reterences}

1. Norton, O.P., Srikantaiah, D.V., and Arunkumar, R, 1991, A direct comparison of cross correlation velocity measurements with laser Doppler measurements. Presented at the AIAA 29th Aerospace Sciences meeting, January 7 - 10, 1991, Reno, Nevada. Paper No. AIAA-91-0213. 


\section{ravk 2. Test stand Operatione}

\section{A Teet stand Modistoationo}

The operating system on the test stand computer was upgraded to the latest version of Hewlett Packard's real-time operating system, and the newest version of PMIS software supplied by Bradley Ward Inc. was also installed. Some of the data collection routines were rewritten and new transducer calibration software was written for the HP3852 data acquisition unit.

The test stand was disassembled for removal of seed and slag deposits and general inspection. All temperature, flow, and pressure transducers were recalibrated.

\subsection{Toet stand Rune}

There were no test stand runs during this quarter. A series of PSD and CARS tests originally scheduled for March were rescheduled for April.

Test runs for the next reporting period will include those already ment loned for the PSD and CARS systems as well as the usual runs prior to a test run at the CFFF. 
Task 3. Technteal support for the Natlonal Mad Program

\section{A Fleld Meacuremente}

While mindful of the mission of this task, there is nothing to report for this quarter.

\subsection{Fleld reote/Inetrument Nodsfloutlone}

While mindful of the mission of this task, there is nothing to report for this quarter.

\section{C Fleld operation/Doveloping oyeteme}

While mindful of the mission of this task, there is nothing to report for this quarter. 


\section{Task 4. Profect Management}

This is an ongoing task considered up to date with the submission of this report. 
Taøk 5. Technology Tranøfer

While mindful of the mission of this task, there is nothing to report for this quarter. 

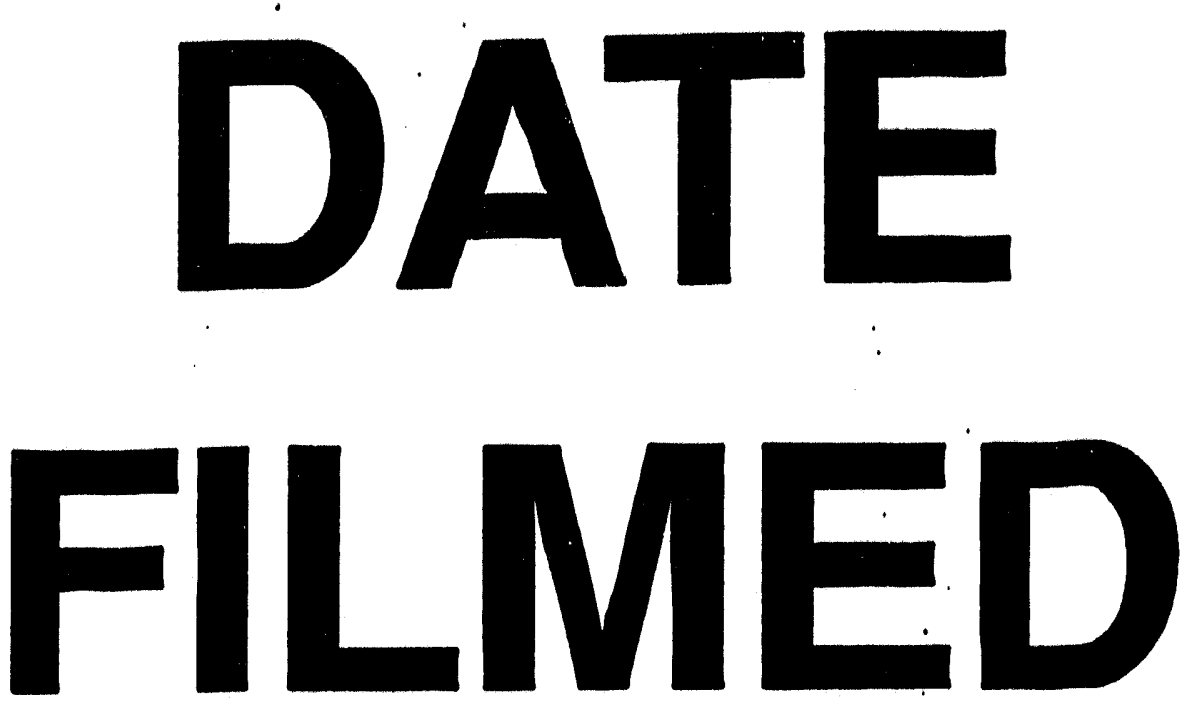

$11 / 4 / 93$
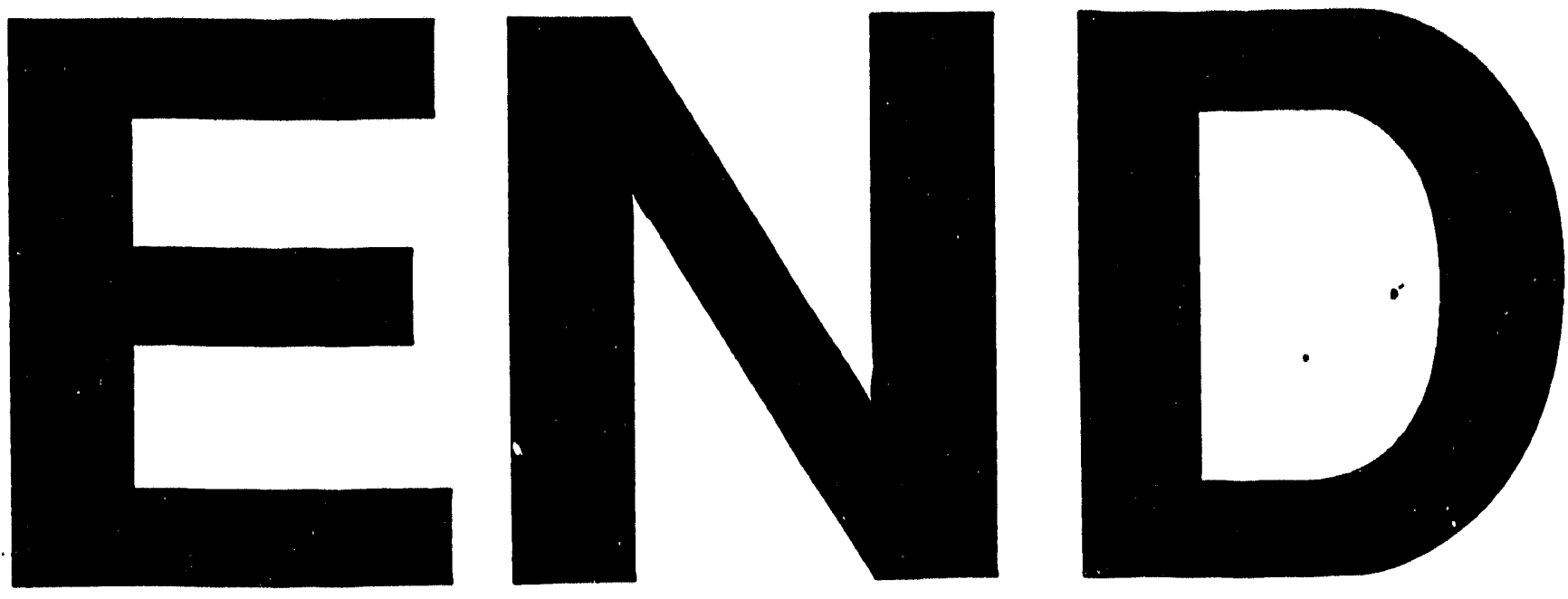
